\title{
Equipment Variables and Deposition Conditions Affecting the Plasma Oxidation of Pyrocarbon Coatings on HTGR Fuel Particles
}

\author{
J.P. Mathers \\ V. J. Tennery \\ E. S. Bomar
}




\section{DISCLAIMER}

This report was prepared as an account of work sponsored by an agency of the United States Government. Neither the United States Government nor any agency Thereof, nor any of their employees, makes any warranty, express or implied, or assumes any legal liability or responsibility for the accuracy, completeness, or usefulness of any information, apparatus, product, or process disclosed, or represents that its use would not infringe privately owned rights. Reference herein to any specific commercial product, process, or service by trade name, trademark, manufacturer, or otherwise does not necessarily constitute or imply its endorsement, recommendation, or favoring by the United States Government or any agency thereof. The views and opinions of authors expressed herein do not necessarily state or reflect those of the United States Government or any agency thereof. 


\section{DISCLAIMER}

Portions of this document may be illegible in electronic image products. Images are produced from the best available original document. 
Printed in the United States of America. Available from National Technical Information Service

U.S. Department of Commerce

5285 Port Royal Road, Springfield, Virginia 22161

Price: Printed Copy \$4.00; Microfiche \$2.25

This report was prepared as an account of work sponsored by the United States Government. Neither the United States nor the Energy Research and Development Administration/United States Nuclear Regulatory Commission, nor any of their employees, nor any of their contractors, subcontractors, or their employees, makes any warranty, express or implied, or assumes any legal liability or responsibility for the accuracy, completeness or usefulness of any information, apparatus, product or process disclosed, or represents that its use would not infringe privately owned rights. 
ORNL/TM-5308

UC-77 (Gas-Cooled

Reactor Technology)

\author{
Contract No. W-7405-eng-26 \\ METALS AND CERAMICS DIVISION \\ HTGR BASE TECHNOLOGY PROGRAM
}

Fueled Graphite Development (189a OHOO2)

EQUIPMENT VARIABLES AND DEPOSITION CONDITIONS AFFECTING THE PLASMA OXIDATION OF PYROCARBON COATINGS ON HTGR FUEL PARTICLES

J. P. Mathers, V. J. Tennery, and E. S. Bomar

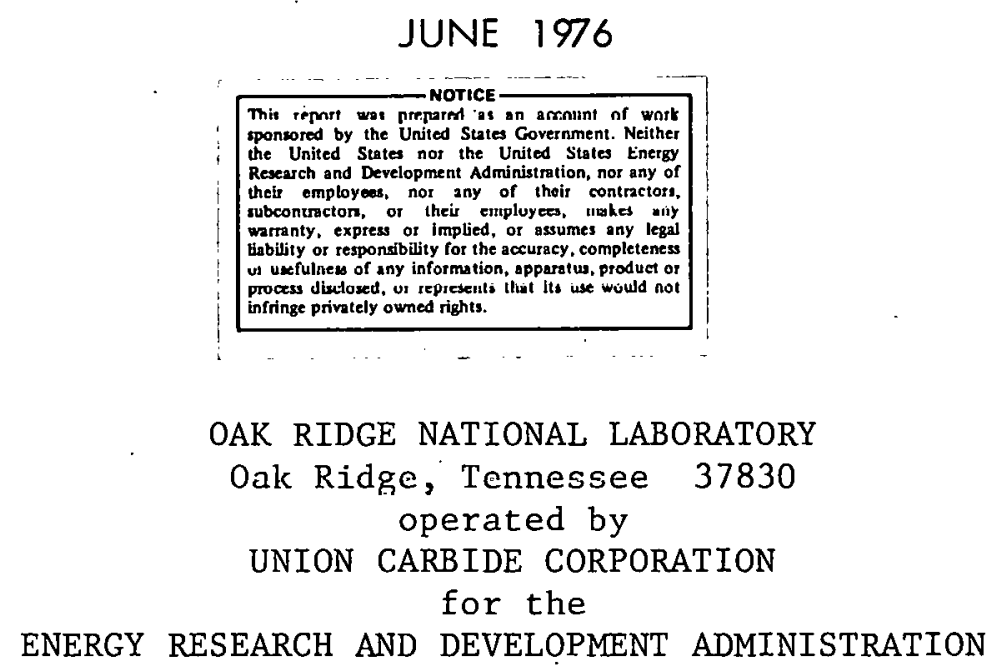


THIS PAGE

\section{WAS INTENTIONALLY LEFT BLANK}


CONTENTS

ABSTRACT . . . . . . . . . . . . . . . . . . . . . . 1

INTRODUCTION . . . . . . . . . . . . . . . . . . . . 2

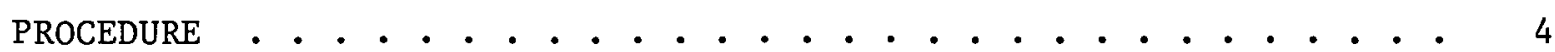

RELATION BETWEEN THE RADIOFREQUENCY POWER LEVEL AND THE PLASMA

OXIDATION OF PYC COATINGS . . . . . . . . . . . . . . 10

USE OF ELONGATED ARRAYS TO ENHANCE THE ETCH GRADIENTS OBTAINED DURING PLASMA OXIDATION AT HIGHER POWER LEVELS . . . . . . . . . . 14

IDENTIFICATION OF IMPURITIES OBSERVED IN THE PLASMA ETCH STRUCTUPE OF PYC COATINCS . . . . . . . . . . . . . . . . . 15

IMTORTANCE OF TIIE LOCATION OF TIIE SAMLE MOUNT IN TIIE LTA : 302

UNIT DURING PLASMA OXIDATION OF PYC COATINGS • • • • • • • • • • .18

ROLE OF THE OXYGEN FLOW RATE IN PLASMA OXIDATION OF PyC COATINGS • • 18

EFFECT OF THE MOUNT TEMPERATURE ON THE PLASMA OXIDATION RATE • • • • 22

EQUIVALENCE OF ETCH STRUCTURE CAUSED BY THE GRADIENT ACROSS A

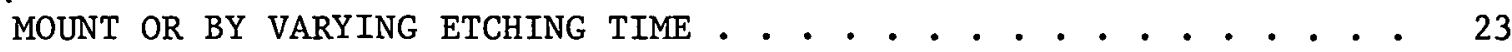

CHANGES IN PyC COATING ETCH STRUCTURE WITH ETCHING TIME • • • • • • 25

RELATIONSHIP BETWEEN PYC COATING DEPOSITION PARAMETERS AND PLASMA

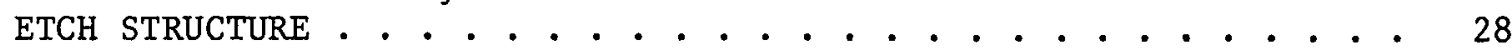

RELATIONSHIP BETWEEN THE INITIAL POROSITY IN THE PYC COATING AND

THE PLASMA ETCH STRUCTURE • . • . . . . . . . . . . . . . . . . . 28

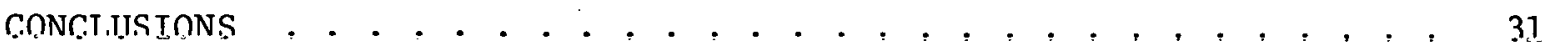

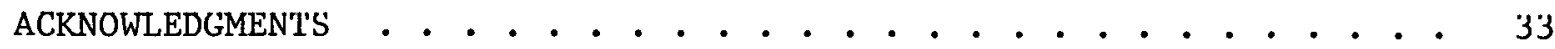


EQUIPMENT VARIABLES AND DEPOSITION CONDITIONS AFFECTING THE PLASMA OXIDATION OF PYROCARBON COATINGS ON HTGR FUEL PARTICLES

J. P. Mathers, ${ }^{1}$ V. J. Tennery, and E. S. Bomar

ABSTRACT

Selective etching with an oxygen plasma is a promising technique for revealing the structure of the high-density pyrocarbon (PyC) coatings used on HTGR nuclear fuel particles and can be used to predict the fast-neutron damage resistance of the PyC. Several factors that affect either the etching rate or the etch structure were examined in this investigation. Particles with PyC coatings deposited from hydrocarbon MAPP gas $\left(\mathrm{C}_{3} \mathrm{H}_{4}\right.$ isomers) under a variety of conditions were polished to the midplane and systematically plasma oxidized to determine the effect of the coating parameters on the observed etch structure. Identical coatings were then oxldized by use of different plasma parameters to determine the relation of the observed etch pattern to these parameters. The concentration of hydrocarbon gas supplied during PyC deposition significantly affected the etch structure of the coatings. Midplane sections of coatings deposited at low MAPP gas concentrations had a ring or concentric shell structure after etching, while those deposited at high gas concentrations had very irregular etch patterns. The etch structure was independent of the coating deposition rate in the range 5.6 to $28 \mu \mathrm{m} / \mathrm{min}$ and was not affected by a change in deposition temperature from 1275 to $1325^{\circ} \mathrm{C}$.

The etching rate of the PyC coating was an increasing function of the radiofrequency power used to excite the plasma and of the temperature of the coatings during the oxidation process. The plasma etching rate also appears to be related to the density of the coating (as measured by the gradient column method) and its deposition temperature. Coatings deposited at $1325^{\circ} \mathrm{C}$ and having densities from 1.84 to $1.96 \mathrm{~g} / \mathrm{cm}^{3}$ etched faster than those deposited at $1275^{\circ} \mathrm{C}$ and having densities from 1.99 to $2.05 \mathrm{~g} / \mathrm{cm}^{3}$.

The etch structures of the coatings change dramatically in certain cases as the etching time is increased. But the dependence on etching time varies for particles having different preparation histories and thus complicates the use of this technique to characterize PyC coatings on HTGR fuel particles. The etch structure is also affected by the distribution of pores in the coatings. High etching rates occurred in localized areas of the coatings where the original pore concentration was high.

\footnotetext{
${ }^{1}$ Present address: Chemical Engineering Division, Argonne National Laboratory, 9700 South Cass Avenue, Argonne, Illinois 60439 .
} 
INTRODUCTION

Coated-particle fuel has been widely accepted for use in hightemperature gas-cooled reactors. ${ }^{2}$ The fuel, in microsphere form, is coated in a fluidized bed with layers of pyrolytic carbon (PyC) and silicon carbide. Two coating schemes are generally used. ${ }^{3}$ The Triso particle has a four-layer structure. A porous inner layer of PyC, called the buffer, provides some storage volume for gaseous fission products that escape from the fuel, and it also absorbs the energy of fission-product recoils. A dense, gastight "isotropic" layer of PyC is deposited over the buffer forming a small pressure vessel, which prevents fission gas from escaping the particle. The next layer is dense silicon carbide, which is highly impervious to gaseous and solid fission products. The final layer of the coating is another dense layer of "isotrop1c" PyC, which provides additional strength to the coating system as well as an interface between the particle and the carbon matrix of the fuel rod in which the particles are embedded. The other coated particle type is referred to as the Biso design, which has only two coatings on the fuel kernel, a buffer and an outer layer of dense "isotropic" PyC.

The dense "isotropic" PyC layers are conventionally designated as LTI (low-temperature isotropic) coatings. This terminology is related to the deposition temperature used in forming the PyC (e.g., 1150 to $1350^{\circ} \mathrm{C}$ ), and the fact that when the deposition conditions are optimized the coatings are structurally nearly isotropic and therefore have good dimensional stability at high fast-neutron fluences. Some of these coatings perform well during irradiation testing, while others deposited under slightly different conditions may perform poorly. To date, it has not been established that conventional metallographic analysis or measurement of structural anistropy by optical techniques alone can predict irradiation behavior.

Recently, Luhleich and his co-workers ${ }^{4-6}$ at Institut für Reaktorwerkstoffe, Kernforschungsanlage Jülich, West Germany, reported success in predicting the irradiation performance of the PyC coatings by a technique referred to as "cold oxidation" or "plasma etching."

${ }^{2}$ W. V. Goeddel, "Coated-Particle Fuels in High-Temperature Reactors: A Summary of Current Applications," Nucl. Appl. 3(10): 599-614 (1967).

${ }^{3}$ o. M. Stansfield, HTGR Fuel Design and Performance, GA-A-13072 ( July 12, 1974).

${ }^{4} \mathrm{H}$. Luhleich et al., "Determination of the Distribution of Amorphous Regions in Pyrocarbon Coatings by Means of 'Cold Oxidation,'" Z. Anal. Chem. 255: 97-103 (1971).

${ }^{5} \mathrm{~K}$. Bongartz et a1., Improvements in Characterization of Pyrolytic Deposited Carbon, JÜL-1078-RW (June 1974).

${ }^{6} \mathrm{H}$. Luhleich et al., "Improvements in Characterization Methods of Pyrocarbon," pp. 27-50 in Quality Control Procedures on .Graphite, Pyrocarbon, and Silicon Carbide, comp. by K. Koizlik, GERHTR-129, JÜL-1106-RW (September 1974). 
In this technique radiofrequency-excited oxygen gas at a pressure of approximately $70 \mathrm{~Pa}$ ( 0.5 torr) is employed to oxidize the PyC coatings of particles that had previously been polished to their midplanes. Preferred oxidation then occurred on a microscopic scale in the PyC coatings to produce characteristic relief patterns or etch structures. They found that different etch structures could be correlated with good or poor irradiation stability.

Luhleich et al. ${ }^{6}$ classified the PyC etch structures that they observed into four categories and related these to the irradiation performance of the coatings as follows:

Type 1 - a layer structure of closed shells, which appears as a series of continuous rings and are concentric about the center of the particle. (These rings are actually alternate regions of heavily and lightly oxidized PyC.);

Type 2 - a layer structure of broken shells, similar to type 1 except that the less-oxidized concentric rings are not continuous circumferentially but are interrupted with zones of more heavily oxidized PyC;

Type 3 - a structure with an inhomogeneous distribution of the heavily oxidized or etched PyC, often characterized by large pockets of the heavily oxidized or etched PyC located somewhat randomly within the coating;

Type 4 - a structure with a homogeneous distribution of the heavily oxidized PyC within the more-oxidation-resistant PyC but with none of the large pockets associated with type 3 .

Sketches of these characteristic patterns as described in ref. 6 are reproduced in Fig. 1.

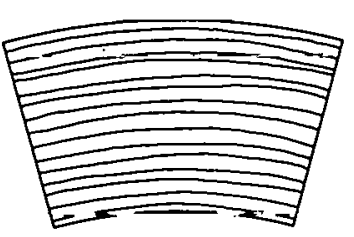

(a) TYPE 1

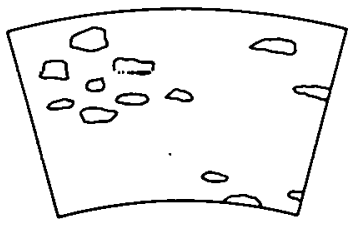

(c) TYPE 3
ORNL- DWG 75-16102

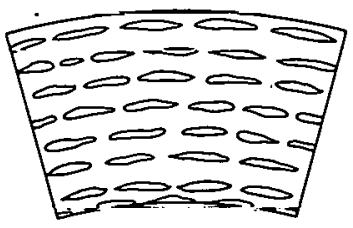

(b) TYPE 2

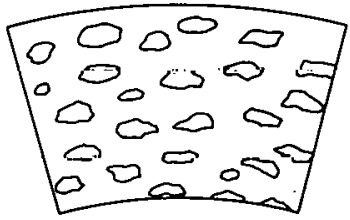

(d) TYPE 4

Fig. 1. Sketches Showing Several Characteristic Etch Patterns for PyC Coatings Following Plasma Oxidation (Adapted from Luhleich et al., GEHRTR-129, PP. 27-50). 
Good irradiation behavior was found to correspond to coatings that exhibited a broken-shell structure (type 2) and with coatings having a homogeneous distribution of more heavily etched PyC (type 4). Type 3 structures may or may not have adequate dimensional stability at high neutron fluences. Type 1 structures are not dimensionally stable at high fast-neutron fluences. Additionally, in structures having good irradiation stability the volume concentration of the more readily oxidizable $\mathrm{PyC}$ in the coating had to exceed about $20 \%$.

Although this characterization technique appears very promising, one difficulty with its application is the subjective nature of the classification of a coating, particularly in the structures of types 2, 3, and 4. Several transition structures are possible between each type, depending on coating deposition conditions; thus categorizing a given coating depends on the experience of the individual evaluating the etch structure.

The purpoes of this study was to examine experimental factors that affect either the rate of oxidation of the PyC or the geometric aspects of the etch structure revealed. Some of the parameters, such as the sample position in the oxidation chamber, relate to specific design features of the oxidation apparatus used in this investigation. Other factors, such as the oxidation time or the effect of residual pores on the development of etch pits in the PyC coatings, are related to the oxidation process itself. No attempt will be made here to relate the observed etch structures to the irradiation performance of the coatings. This will be reported later in results for capsules $\mathrm{HT}-28,-29$, and -30 , which were irradiated in the target position of the high flux isotope reactor. We were primarily interested in gaining information about (1) the plasma oxidation process itself, (2) the operational characteristics of a commercial unit used to accomplish the etching, and (3) those factors that are most critical for application of the technique to PyC coatings on HTGR fuel particles.

\section{PROCEDURE}

The plasma oxidation unit which was used during this study was an LTA-302, Low-Temperature Asher, ${ }^{7}$ shown in Fig. 2. This unit has two individual oxidation chambers, and each chamber can accommodate a maximum of two standard metallographic sample mounts. One of these chambers is shown schematically in Fig. 3. During operation, it is evacuated by a mechanical vacuum pump, and oxygen is admitted at the top of each chamber. The total flow is regulated by a needle valve to values in the range 0 to $450 \mathrm{~cm}^{3} / \mathrm{min}$ at flowmeter conditions [about $24^{\circ} \mathrm{C}\left(75^{\circ} \mathrm{F}\right)$ and $<14 \mathrm{kPa}$ (2 psia)]. Since the chambers are in parallel, each is assumed to receive half of the total. To achieve a relatively stable plasma, the flow rate is adjusted to maintain an absolute oxygen pressure of 100 to $240 \mathrm{~Pa}(0.75-1.8$ torr) in the chamber. The pressure in the chamber is monitored continuously by a thermocouple vacuum gage. As the

\footnotetext{
${ }^{7}$ LFE Corporation, Waltham, Massachusetts.
} 


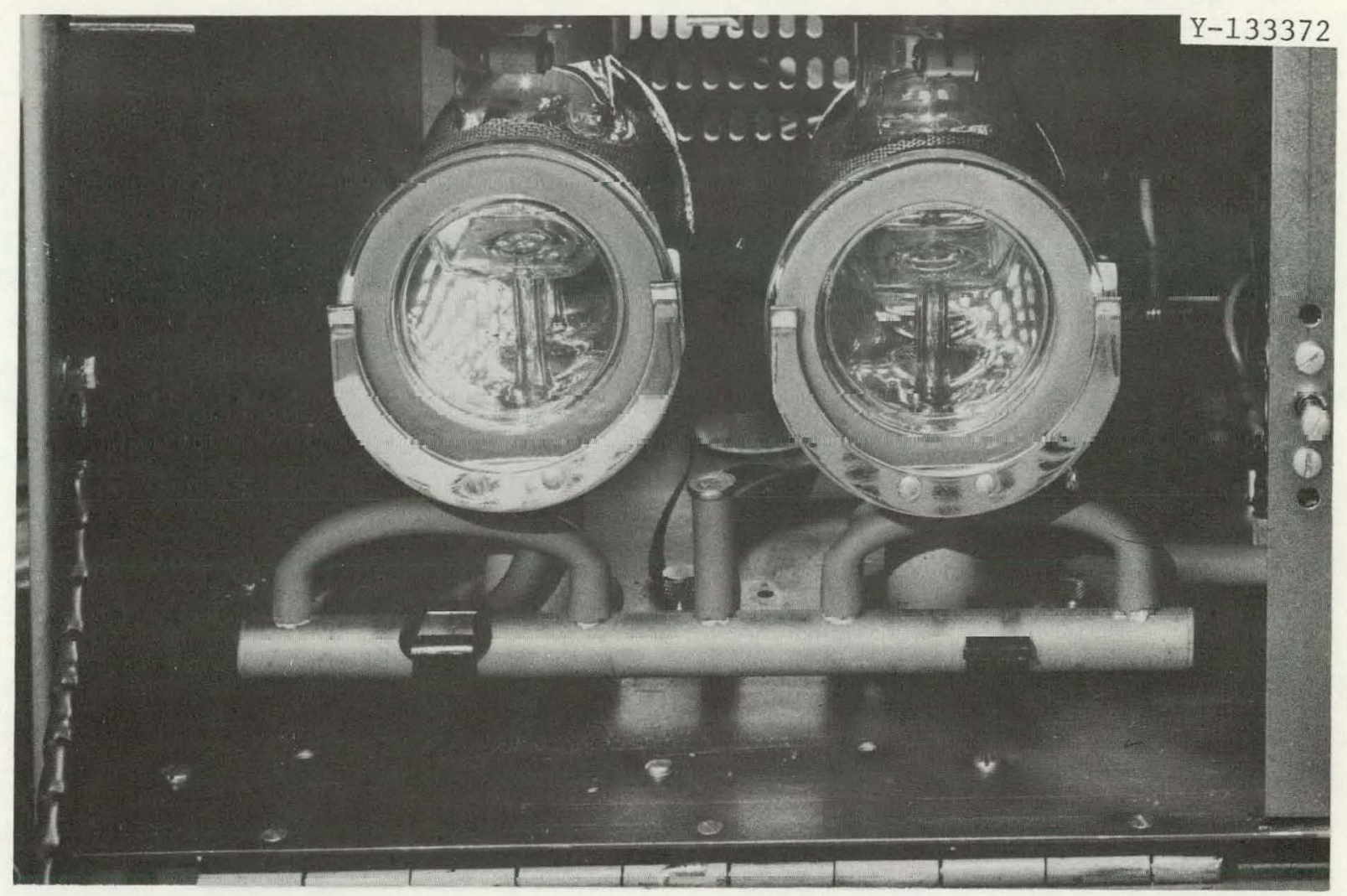

Fig. 2. The LTA-302 Low-Temperature Asher.

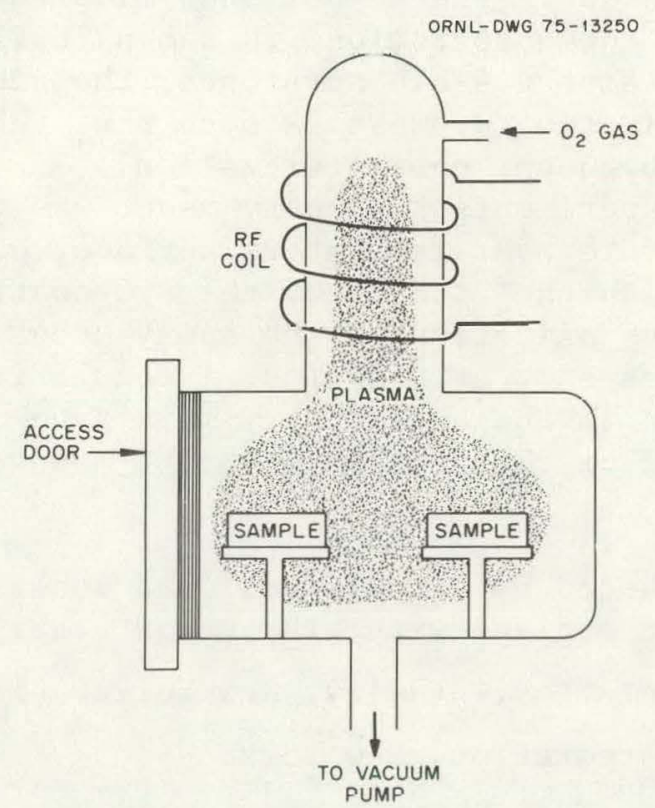

Fig. 3. Side View of Oxidation Chamber in the LTA-302 LowTemperature Asher. 
oxygen enters the chamber it passes through a radiofrequency ( $\mathrm{rf}$ ) induction coil where the rf field at $13.56 \mathrm{MHz}$ dissociates the gas into atomic oxygen and generates a plasma. The energy used to excile the oxygen is controlled by the rf power input to the coil. Both chambers are connected in parallel to the oxygen supply, vacuum, and rf generator; thus a common set of controls is used for the two chambers and it is assumed that the plasma in both chambers has the same potential for oxidizing PyC coatings. The LTA-302 is capable of a total rf power output of 0 to $300 \mathrm{~W}$ ( 0 to $150 \mathrm{~W}$ per chamber). In this work we used power levels of 20 to $40 \mathrm{~W}$ per chamber and an oxygen flow rate of approximately $75 \mathrm{~cm}^{3} / \mathrm{min}$ per chamber except where effects of oxygen flow rate were being studied. This resulted in a chamber pressure of $100 \mathrm{~Pa}$ ( 0.75 torr) .

The fuel particles used in this study were Biso-coated $\mathrm{ThO}_{2}$. The buffer layers were deposited from acetylene and the high-density PyC coatings were deposited from $\mathrm{MAPP}^{8}$ gas under a wide range of coating conditions, as shown in l'able 1 .

The particlca werc mounted in a circular array, approximately $10 \mathrm{~mm}$ in diameter, with Araldite $502^{9}$ used as the mounting material in earlier samples. Epoxy resin was used because the mounl had lo be nonconducting to prevent excessive heating of the mount by eddy currents induced by the rf field. After mounting, the particles were ground to their midplanes and then polished. A typical sample mount is shown in Fig. 4. When the particles were ground to their midplanes, the fuel kernels were easily separated from the coatings, and, for convenience, these were removed from the mount at this time. This work used a preparation procedure consisting of grinding the mounted coated particles on successively finer SiC papers, down to 600 grit, followed by 5 min of polishing with a Linde A alumina ${ }^{10}$ suspended in water. This procedure required considerably less time than for routine metallographic examination. The as-polished midplane surface of a PyC coating following these operations is shown in Fig. 5. Although the surface still contains visible scratches, the amount of PyC removed during the oxidation process is such that the scratches are not detrimental to subsequent characterization.

In our initial experiments the epoxy mount was oxidized by the plasma at a very low rate over its entire surface, but this did not appear to interfere with the etching of the PyC coatings. However, in several cases, heavy oxidation of the epoxy occurred in localized areas, usua $\perp$ y on an edge or at a surface Irregularily Llial was located near the plasma column in the apparatus. This type of oxidation resulted in carbonized or charred spots on the mounts and changed the

${ }^{8}$ MAPP yas is marketed by Airco, Inc., and consists primarily of methylacetylene and propadiene with alkanes as stabilizers.

${ }^{9}$ CIBA-Giegy Corporation, Ardsley, New York.

${ }^{10}$ Union Carbide Corporation, New York. 
Table 1. Deposition Conditions and Densities of the LTI Coatings ${ }^{a}$

\begin{tabular}{|c|c|c|c|c|}
\hline $\begin{array}{c}\text { MAPP }^{\mathrm{b}} \text { Gas } \\
\text { Concentration } \\
(\%)\end{array}$ & $\begin{array}{c}\text { Deposition } \\
\text { Temperature } \\
\left({ }^{\circ} \mathrm{C}\right)\end{array}$ & $\begin{array}{c}\text { Deposition } \\
\text { Rate }^{\mathrm{d}} \\
(\mu \mathrm{m} / \mathrm{min})\end{array}$ & $\begin{array}{l}\text { Densitye } \\
\left(\mathrm{g} / \mathrm{cm}^{3}\right)\end{array}$ & Batch \\
\hline 100 & 1275 & 23.0 & 2.05 & OR-2275-AHT \\
\hline 100 & 1275 & 14.1 & 2.02 & OR-2266-HT \\
\hline 100 & 1275 & $7.3^{f}$ & 1.98 & OR-2291-HT \\
\hline 100 & 1275 & $4.9^{f}$ & 1.98 & OR-2297-AHT \\
\hline 100 & 1325 & 28.0 & 1.96 & OR-2274-HT \\
\hline 100 & 1325 & 15.7 & 1.95 & OR-2265-HT \\
\hline 100 & 1325 & $8.6^{f}$ & 1.88 & OR-2290-HT \\
\hline 100 & 1325 & $5.6^{\mathrm{f}}$ & 1.90 & OR-2296-AHT \\
\hline 50 & 1275 & 10.7 & 2.02 & OR-2271-HT \\
\hline 50 & 1275 & 6.5 & 2.01 & OR-2262-HT \\
\hline 50 & 1275 & $3.6^{f}$ & 1.96 & OR-2294-HT \\
\hline 50 & 1275 & $2.3^{f}$ & 1.91 & OR-2299-HT \\
\hline 50 & 1325 & 12.5 & 1.91 & OR-2269-HT \\
\hline 50 & 1325 & 7.4 & 1.89 & OR-2261-HT \\
\hline 50 & 1325 & $3.9^{\mathrm{f}}$ & 1.83 & OR-2293-HT \\
\hline 50 & 1325 & $2.5^{f}$ & 1.82 & OR-2298-HT \\
\hline 25 & 1275 & 5.2 & 2.01 & OR-2273-HT \\
\hline 25 & 1275 & 3.2 & 1.99 & OR-2264-HT \\
\hline 25 & 1275 & $1.8^{f}$ & 1.91 & $\mathrm{NR}-2295-\mathrm{HT}$ \\
\hline 25 & 1325 & 6.2 & 1.86 & $\mathrm{OR}-2272-\mathrm{HT}$ \\
\hline 25 & 1325 & 3.6 & 1.84 & OR-2263-HT \\
\hline 15 & 1275 & 3.1 & 1.98 & OR-2276-HT \\
\hline
\end{tabular}

a Reference design for all particles is a $300-\mu \mathrm{m} \mathrm{ThO}_{2}$ kernel, 85- $\mu \mathrm{m}$ buffer, $85-\mu \mathrm{m}$ LTI. A11 batches were annealed for $15 \mathrm{~min}$ at $1800^{\circ} \mathrm{C}$ after coating.

${ }^{b}$ MAPP gas is marketed by Airco, Inc, and consists primarily of methylacetylene and propadiene with alkanes as stabilizers.

${ }^{c}$ Argon diluent.

determined from coating time and microradiographic thickness measurement.

Measured by gradient column technique.

${ }^{f}$ Fluidized bed diluted with low-density, inert particles for coating, thereby reducing total gas flux requirement and deposition rate for given hydrocarbon concentration. 


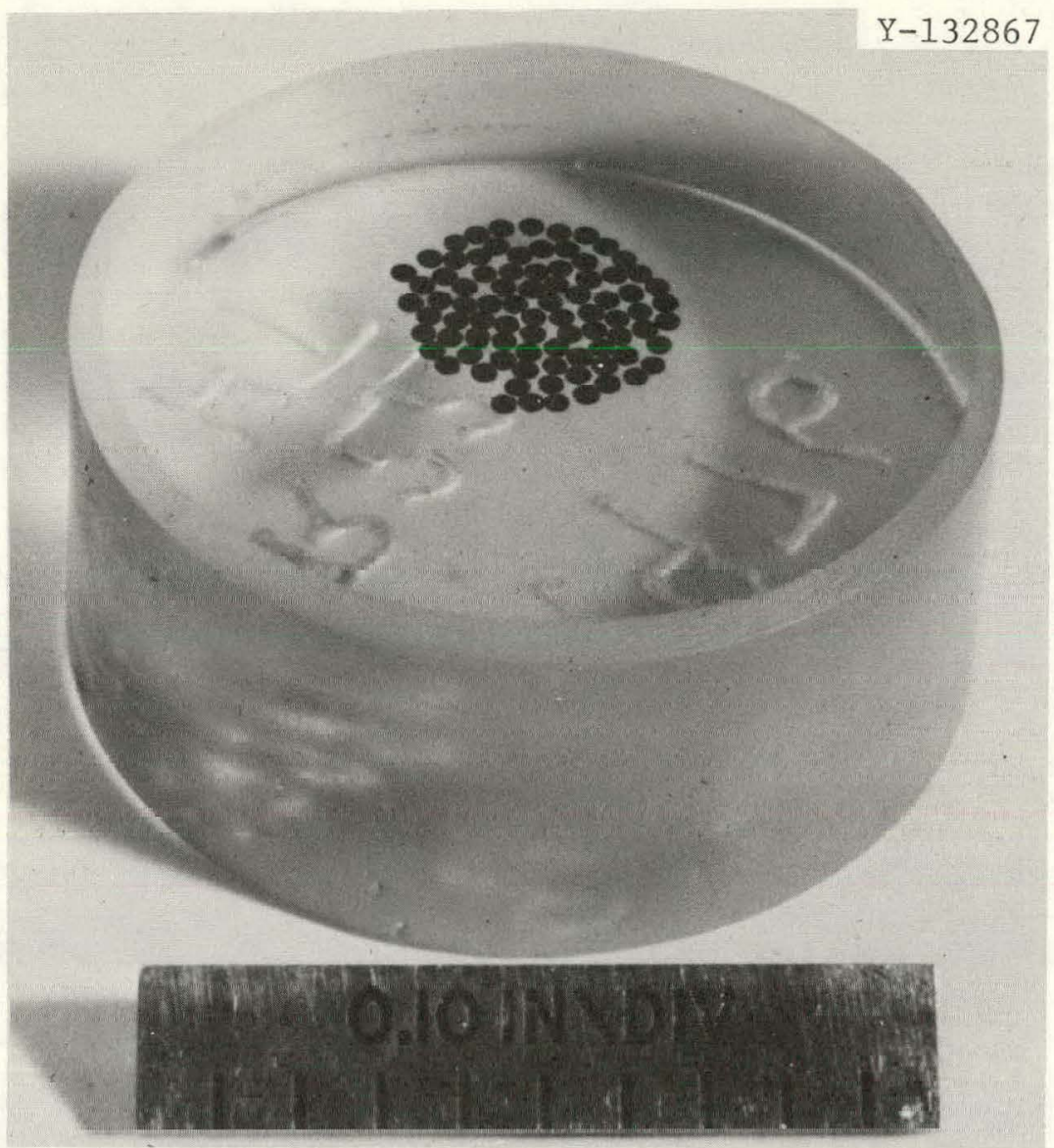

Fig. 4. A Sample Mount for Plasma Oxidation. Scale is $2.5 \mathrm{~mm} /$ division.

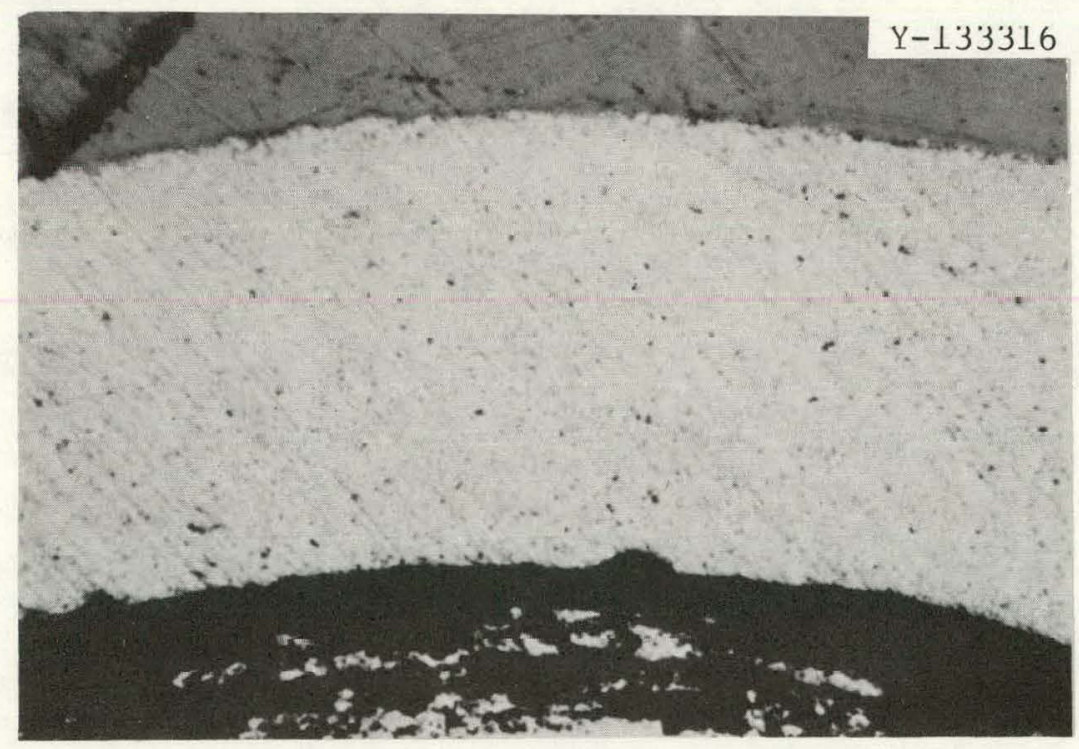

Fig. 5. The As-Polished Condititon of the LTI Before Plasma Oxidation. $500 \times$. 
plasma color from its normal light purple to a bright blue. The result was appreciable heating and deformation of the mount, which made it necessary to stop the etching operation, cool the mount, and reposition it in the oxidation chamber. This interfered with development of a standard etching procedure. To eliminate this problem two approaches were investigated. First, since the carbonized resin was usually located at the top edge of the mount, we attempted to protect this edge with a Pyrex glass cap. One cap design consisted of a ring that was supported by a shoulder machined in the side of the mount, as shown in Fig. 6(a). This type of protection was helpful but was not totally effective since gross oxidation and carbonization of the resin still occurred on the vertical cylindrical surface of some samples where the mount contacted the glass ring. A second cap design was evaluated and proved successful. This cap, shown in Fig. 6(b), completely covered the top edge of the mount while still exposing the coated particle array to the plasma. In the second approach, we evaluated another type of epoxy resin to see if it was more stable to oxidation by the plasma. We compared the performance of the Araldite 502 epoxy with Epon 815.11 Blank cylindrical mounts of each epoxy type were plasma oxidized for 10-min intervals using protective cover caps at rf power levels of $20,30,40$, and $50 \mathrm{~W}$ per chamber. The Araldite mounts carbonized on the bottom edges at $40 \mathrm{~W}$ per chamber, but the Epon 815 did not carbonize at any of these power levels. Therefore, we chose the Epon 815 epoxy for use in all subsequent mounts. No further problems were experienced with the mounts during the course of this work when the Epon 815 epoxy and Pyrex glass cover caps were used.

${ }^{11}$ Shell Chemical Company, Houston, Texas.

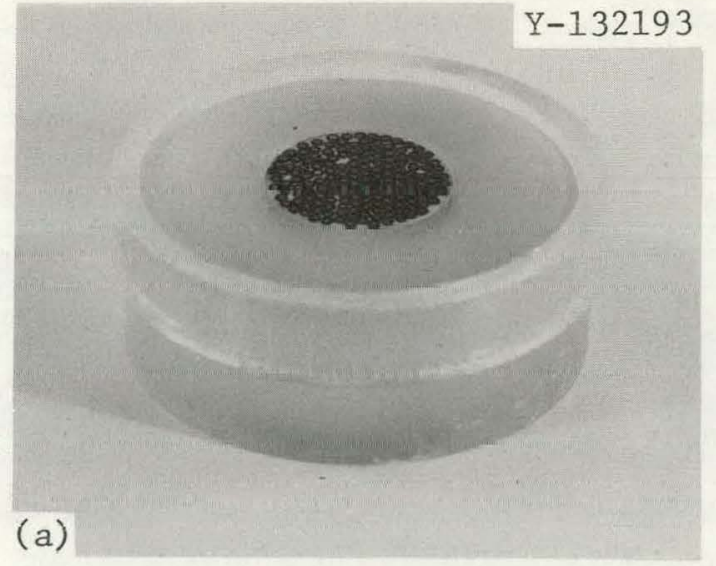

Fig. 6. Protective Caps. 1.5x.

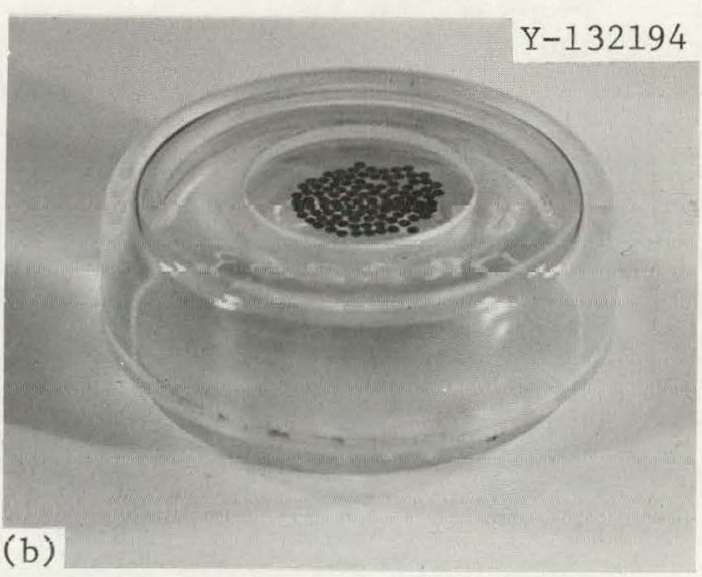

(a) Ring type. (b) Cover type. 
The etching procedure employed during this investigation, unless otherwise specified, was as follows: The capped mount containing the polished coatings was placed in the front sample position of the righthand chamber (as one faces the LTA-302). Then the chamber was evacuated and the oxygen flow adjusted to $75 \mathrm{std} \mathrm{cm}^{3} / \mathrm{min}$ per chamber. The rf power was adjusted to the desired level. Samples were oxidized for 10-min intervals and examined under dark-field illumination with a microscope. ${ }^{12}$ This procedure was repeated until the desired degree of etching was obtained. As the desired etch condition was approached, the time period of the last few oxidation intervals was often reduced to avoid overetching the sample. We found, in agreement with Luhliech et al., ${ }^{13}$ that the etched structure is easily revealed by dark-field illumination, while any structural detail is difficult to distinguish under brightfield or oblique illumination. One difficulty with using this technique was lack of an objective basis for judging when a coating was properly etched, especially since some of the etch structures appeared to change almost continuously from one type to another as the total etching time ot a specitic coating was increased. Theretore, we arbitrarily selected the final state of etching of a coating as that observed when the coating had sufficient surface relief to reveal one of the structures described by Luhliech et $a 1 .{ }^{13}$ and shown in Fig. 1. If a coating was etched too long, most of the surface structural detail was lost. Also, in heavily etched coatings, the oxidation in some areas of the coating progressed so far ahead of the rest of the coating that the resulting surface roughness made it impossible to keep the entire surface within the focal depth of the $40 \times$ dark-field objective of the microscope.

\section{RELATION BETWEEN THE RADIOFREQUENCY POWER LEVEL AND THE PLASMA OXIDATION OF PyC COATINGS}

To determine the effect of the rf power level on the PyC etching rate and the resulting etch structure, the following experiment was conducted: Seven coating types deposited under a wide variety of conditions were selected from the 22 coatings listed in Table 1 . The coatings were etched at rf power levels of 20,30 , and $40 \mathrm{~W}$ per chamber in 10-min intervals. The total time required to final etch the PyC coating at each power level was recorded and a dark-field photomicrograph made of the etched structure. As mentioned earlier, some degree of ambiguity is involved in deciding upon the final state of etch to be

${ }^{12}$ Bausch and Lomb Mode1 Research II.

${ }^{13} \mathrm{H}$. Luhliech et al., "Improvements in Characterization Methods of Pyrocarbon," pp. 27-50 in Quality Control Procedures on Graphite, Pyrocarbon, and Silicon Carbide, comp. by K. Koizlik, GERHTR-129, JÜL-1106-RW (September 1974). 
used for evaluating PyC coatings. Therefore, in this experiment, each coating type was etched initially at the lowest rf power level of $20 \mathrm{~W}$ per chamber until the PyC coating achieved a surface relief that was arbitrarily selected as an end point for that specific coating. For other specimens of the same coating we attempted to obtain the same degree of etching at the higher power levels.

The relationship between the rf power and the etching time is shown in Table 2. Note that the etching time is greatly reduced at higher power levels for coatings that etch slowly at the lower power levels, and there is much less difference in the etching rates of coatings that etch rapidly at lower power levels. The etching rate appears to depend on the coating deposition temperature and the density of the annealed coating. Higher etching rates are observed for those coatings that have the lowest densities and were deposited at the higher temperature. Although the etching time was greatly reduced at the higher rf power levels, it was much more difficult to control the etching process. This was because only one or two etching cycles were typically required to achieve the desired amount of etching, and we could not monitor the etching progress satisfactorily to avoid overetching some specimens. The etch structures obtained at the different power levels appeared to be almost identical for a given coating. Examples of the structures obtained for two of the coatings for different power levels are shown in Figs. 7 and 8 .

Table 2. Effect of Power Level on the Total Etching Time of PyC Coatings on Biso-Coated Particles Prepared Under Various Conditions

\begin{tabular}{|c|c|c|c|c|c|c|c|}
\hline \multirow{3}{*}{ Sample } & \multirow{2}{*}{\multicolumn{3}{|c|}{$\begin{array}{l}\text { Total Etching Time, min, } \\
\text { at Each Chamber Power }\end{array}$}} & \multicolumn{3}{|c|}{ Deposition Conditions } & \multirow{3}{*}{$\begin{array}{l}\text { Density } \\
\left(\mathrm{g} / \mathrm{cm}^{3}\right)\end{array}$} \\
\hline & & & & \multirow{2}{*}{$\begin{array}{l}\text { MAPP } \\
\text { Gas } \\
(\%)\end{array}$} & \multirow{2}{*}{$\begin{array}{c}\text { Rate } \\
(1 / \mathrm{m} / \mathrm{min})\end{array}$} & \multirow{2}{*}{$\begin{array}{l}\text { Temper- } \\
\text { ature } \\
\left({ }^{\circ} \mathrm{C}\right)\end{array}$} & \\
\hline & $20 \mathrm{~W}$ & $30 \mathrm{~W}$ & $40 \mathrm{~W}$ & & & & \\
\hline OR-2264-HT & 60 & 20 & 20 & 25 & 3.2 & 1275 & 1.99 \\
\hline OR-2271-HT & 50 & 20 & 12 & 50 & 10.7 & 1275 & 2.02 \\
\hline OR-2275-AHT & 40 & 15 & 10 & 100 & 23.0 & 1275 & 2.05 \\
\hline $\mathrm{OR}-2295-\mathrm{HT}$ & 30 & 15 & 12 & 25 & 1.8 & 1275 & 1.91 \\
\hline $\mathrm{OR}-2274-\mathrm{HT}$ & 30 & 10 & 10 & 100 & 28.0 & 1325 & 1.96 \\
\hline OR-2263-HT & 20 & 10 & 10 & 25 & 3.6 & 1325 & 1.84 \\
\hline OR-2269-HT & 10 & 10 & 8 & 50 & 12.5 & 1325 & 1.91 \\
\hline
\end{tabular}



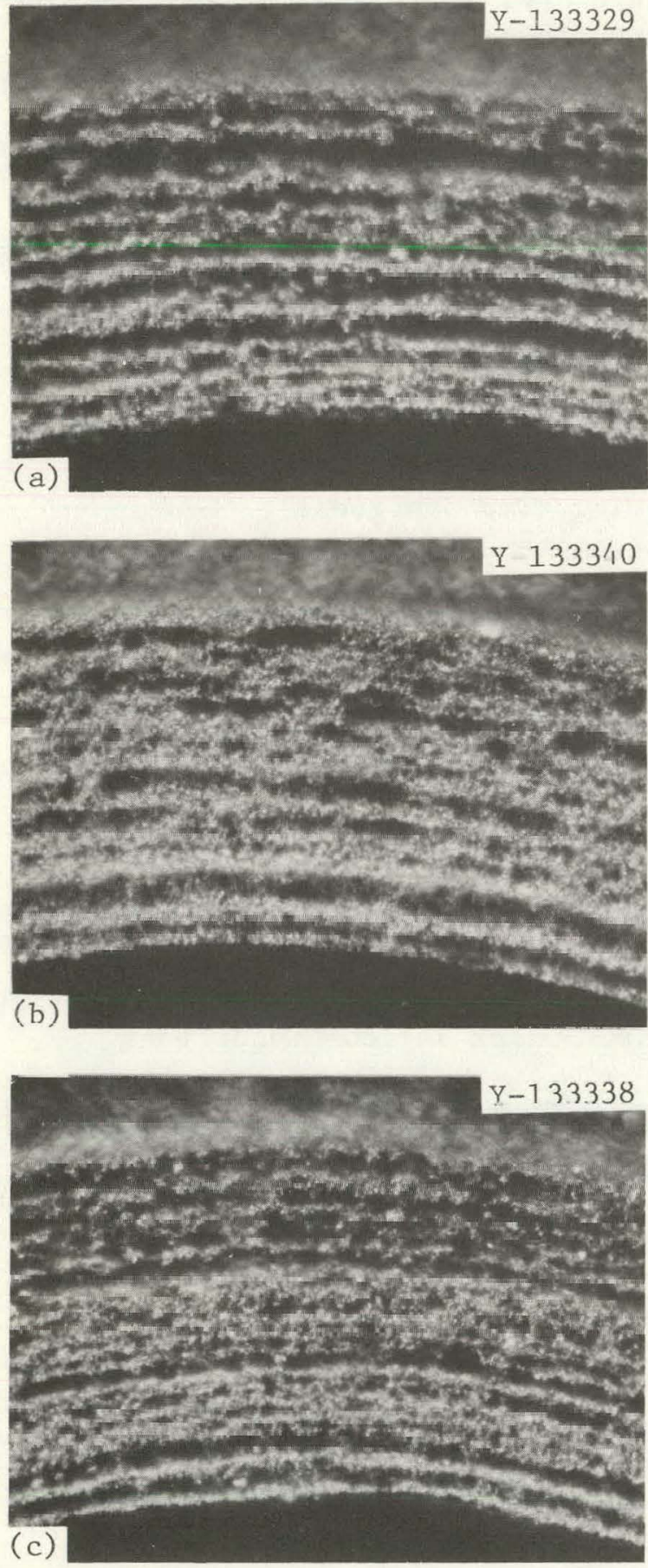

Fig. 7. The Etch Structures Obtained for Coating OR-2263-HT. Dark field illumination. 500x. (a) $20 \mathrm{~W}$ per chamber. (b) $30 \mathrm{~W}$ per chamber. (c) $40 \mathrm{~W}$ per chamber.
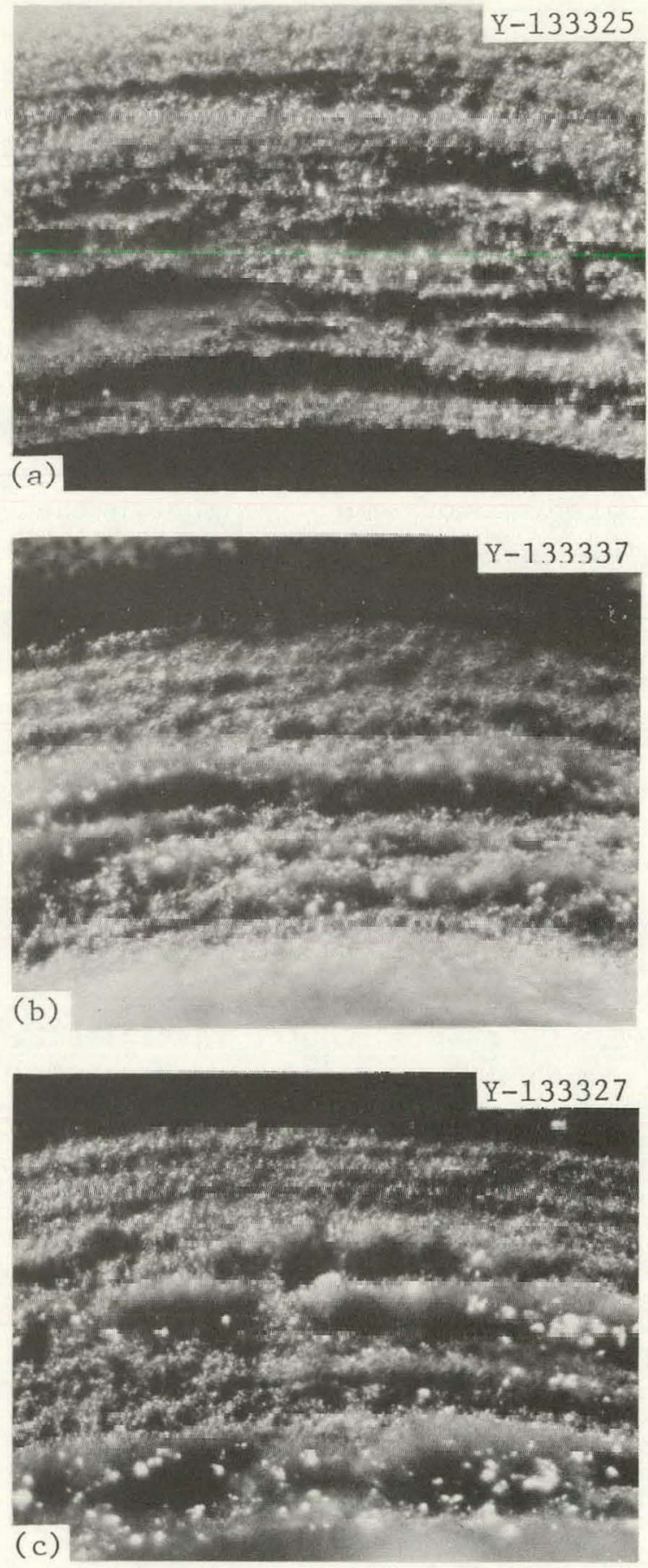

Fig. 8. The Etch Structures Obtained for Coating OR-2274-HT. Dark field illumination. 500x.

(a) $20 \mathrm{~W}$ per chamber. (b) $30 \mathrm{~W}$ per chamber. (c) $40 \mathrm{~W}$ per chamber. 
The photomicrographs of Figs. 7 and 8 are characteristic of the etch structures found in the coatings located near the center of the particle array in the mount. Typically coatings near the midradius of the particle array were etched to a lesser extent, and those at the very edge exhibited almost no etching. An example of one etch gradient is shown in Fig. 9 for coating OR-2274-HT, which was etched for $30 \mathrm{~min}$ at $20 \mathrm{~W}$ per chamber. At higher power levels the degree of etching varied less, as seen in Fig. 10, where the gradient is shown for the same coating after a 10-min etch at $40 \mathrm{~W}$ per chamber. These gradients proved to be useful because they reduced the chances of inadvertently overetching all the coatings in a given sample mount during a 10-min exposure to the plasma.
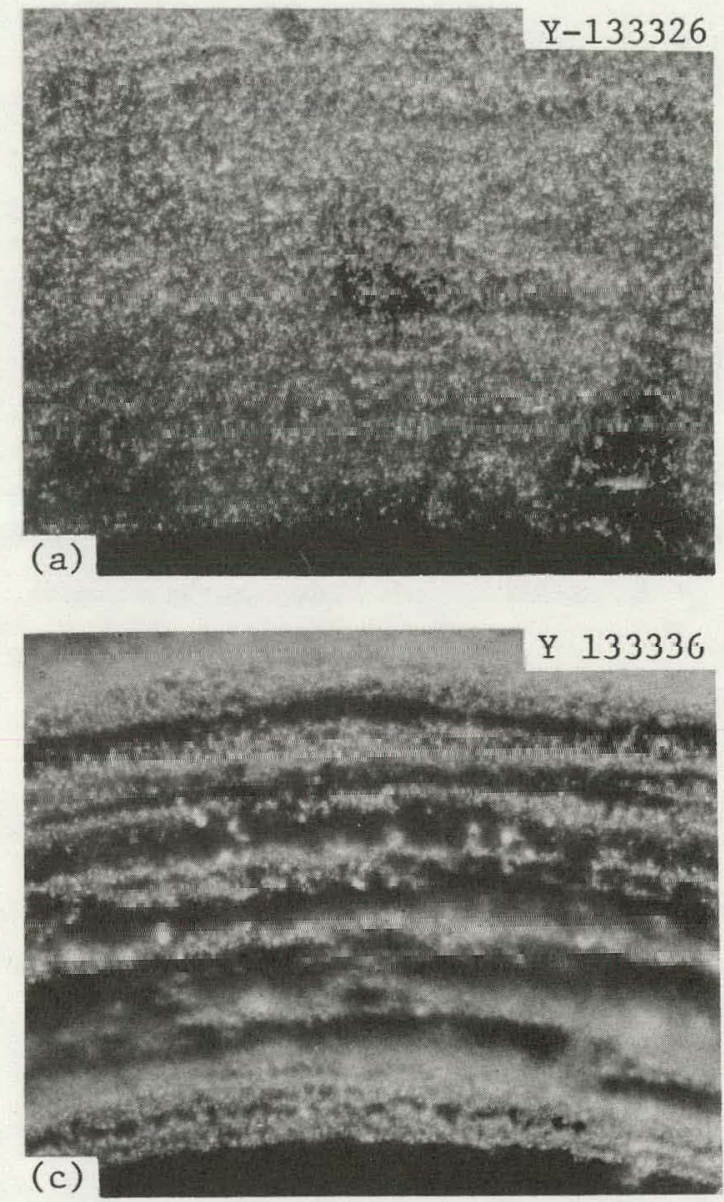
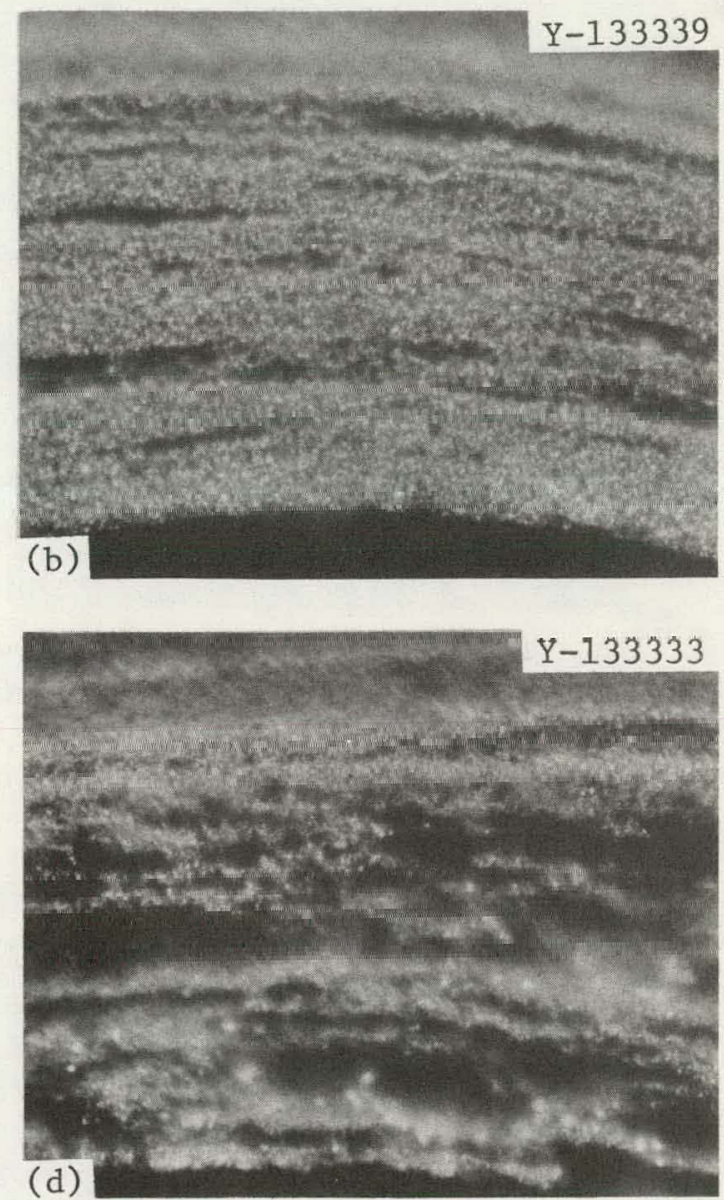

(d)

Fig. 9. The Etch Gradient Observed in Dark Field Illumination for Coating OR-2274-HT at $20 \mathrm{~W}$ per Chamber. 500x. (a) Outside edge of array. (b) Near the outside edge of the array. (c) Near the midradius of the array. (d) Near the center of the array. 

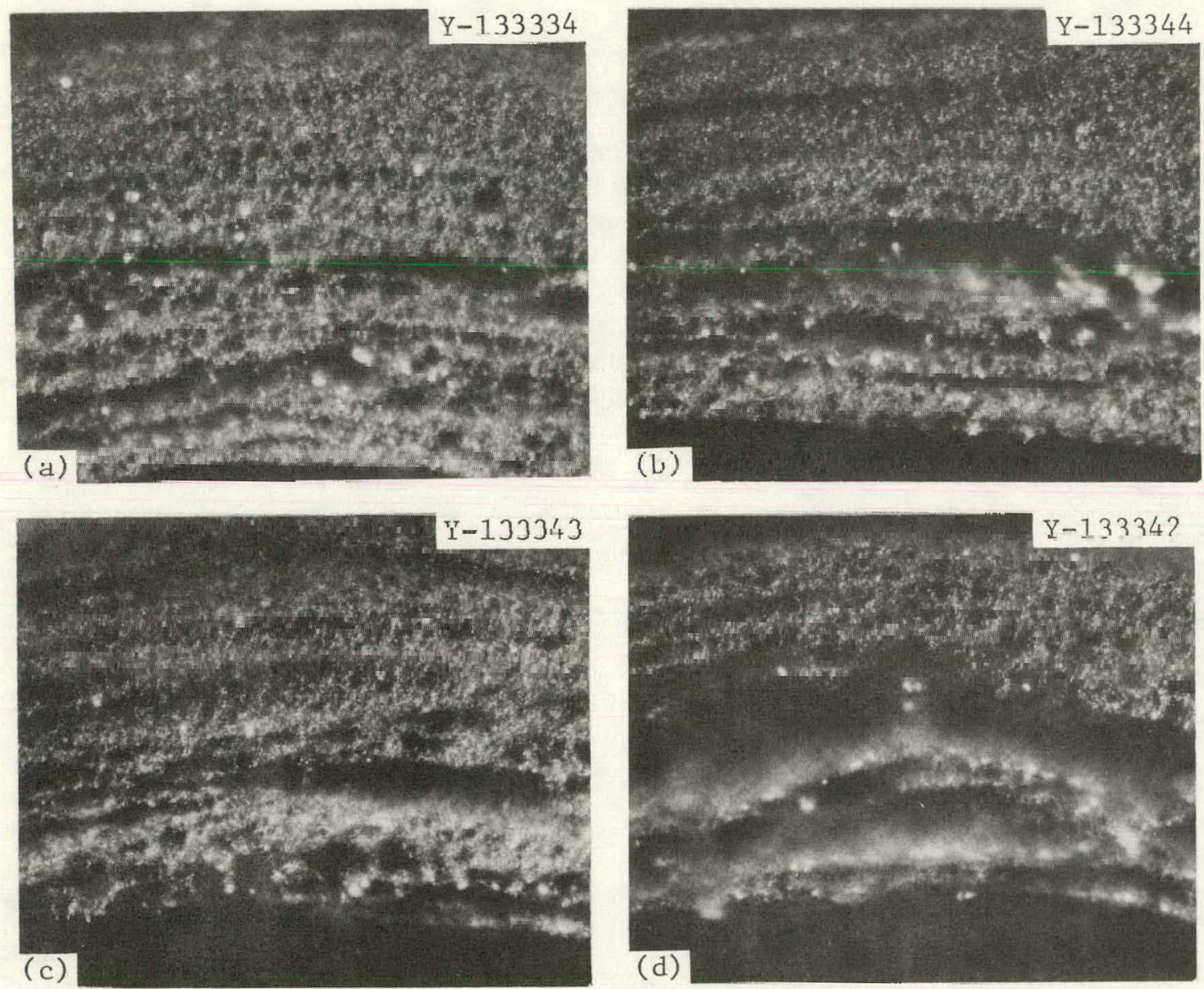

Fig. 10. The Etch Gradient Observed in Dark Field Illumination for Coating OR-2274-HT at $40 \mathrm{~W}$ per Chamber. bUUx. (a) Uutside edge of the array. (b) Near the outside edge of the array. (c) Near the midradius of the array. (d) Near the center of the array.

\section{USE OF ELONGATED ARRAYS TO ENHANCE THE ETCH GRADIENTS OBTAINED DURING PLASMA OXIDATION AT HIGHER POWER LEVELS}

The etching times in Table 2 for the samples etched at $40 \mathrm{~W}$ per chamber are all within the range from 8 to $20 \mathrm{~min}$. Since the etch gradient helps to reduce the possibility of overelching all the coatings in a mount during an elching interva1, it appeared possible that a standard etching time might be used on a wide variety of coating types if their gradients could be enhanced at the higher rf power levels. We attempted to do this by mounting the particles in an elongated rectangular array, approximately 4 by $15 \mathrm{~mm}$, as shown in Fig. 11. Samples of the seven coatings listed in Table 2 were mounted in the elongated arrays and then etched for $12 \mathrm{~min}$ at $40 \mathrm{~W}$ per chamber. The mounts were positioned in the front of the oxidation chamber with the 


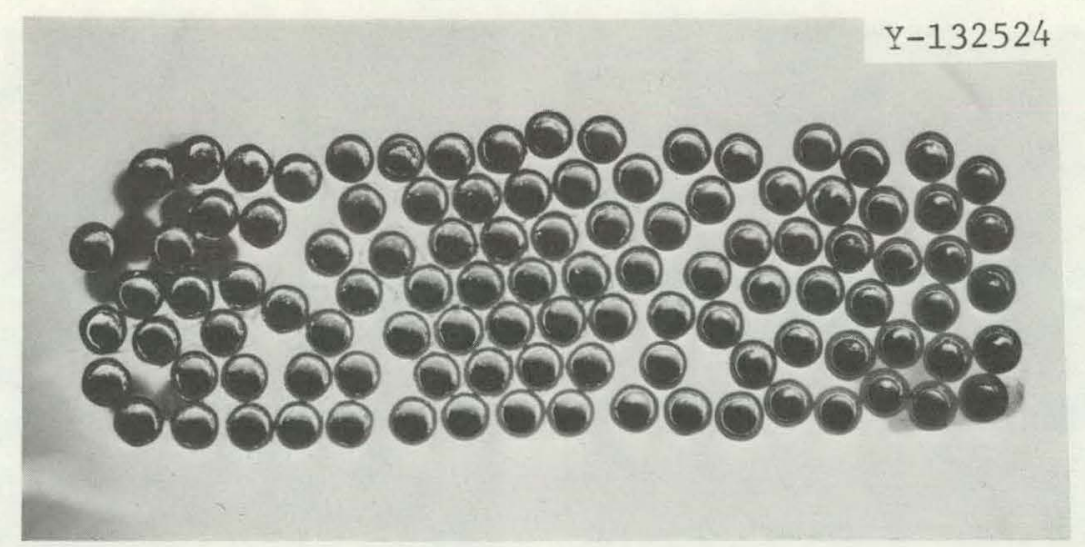

Fig. 11. An Elongated Array. 7x.

length of the array extending between the plasma column and the access door. After etching, all the sample mounts contained good etch gradients, even though some of the particles in the center of the array were badly overetched. The gradient observed in the mount of coating OR-2274-HT is shown in Fig. 12. Compare this gradient with that obtained for the same coating by use of the circular array at $40 \mathrm{~W}$ per chamber, Fig. 10. By properly designing the sample array to maximize the etching gradient it appears possible to use a standard etching time for a variety of PyC coating types.

\section{IDENTIFICATION OF IMPURITIES OBSERVED IN THE PLASMA ETCH STRUCTURE OF PYC COATINGS}

During our etching experiments we often observed a white deposit that covered the inner surface of the coatings after they were plasma oxidized, as shown in Fig. 13. With an energy-dispersive x-ray analyzer attachment to a scanning electron microscope (SEM), we were able to identify aluminum in the deposit and so concluded that the material was probably aluminum oxide. Since aluminum oxide is used in specimen polishing, we believe that the aluminum oxide penetrates the porosity in the buffer layer of the coating and becomes visible as the buffer is subsequently oxidized. Some of this alumina is also occasionally seen in the etched PyC coating structures. A similar situation was observed in coatings that had been given a normal metallographic polish, including the use of diamond paste. In the latter case, however, much more of the white debris was found in the etched PyC, as shown in Fig. 14. This material showed a strong silicon peak during $\mathrm{x}$-ray analysis and is apparently a remnant of a silicon compound used in the diamond paste. 

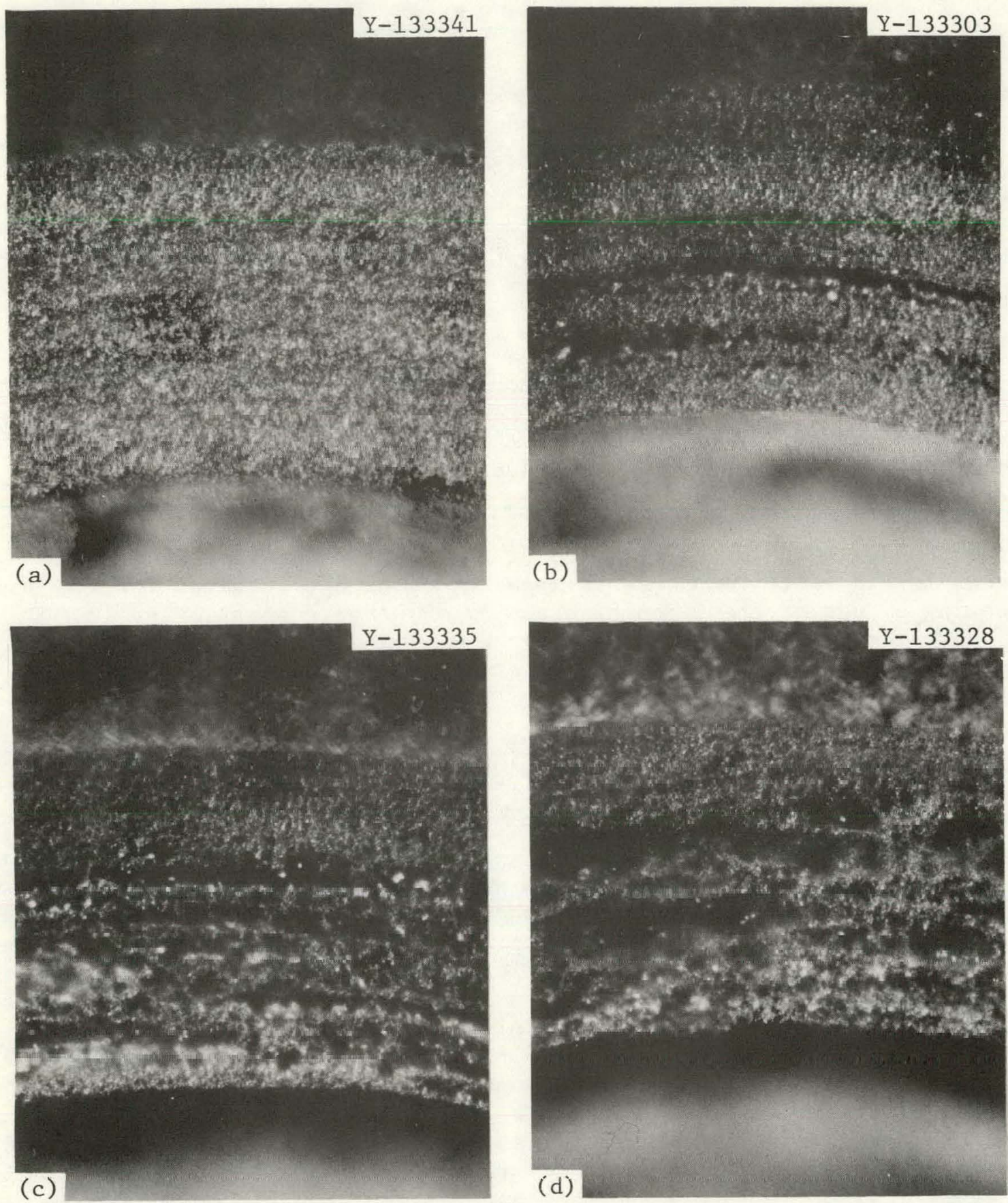

Fig. 12. The Etching Gradient Observed in Dark Field Illumination for Coating OR-2274-HT at $40 \mathrm{~W}$ per Chamber with an Elongated Array. 500x. (a) The edge of the array closest to the chamber door. (b) Near the edge of the array closest to the chamber door. (c) Also near the edge of the array and closest to the chamber door. (d) Midway between the center and the edge closest to the chamber door. 


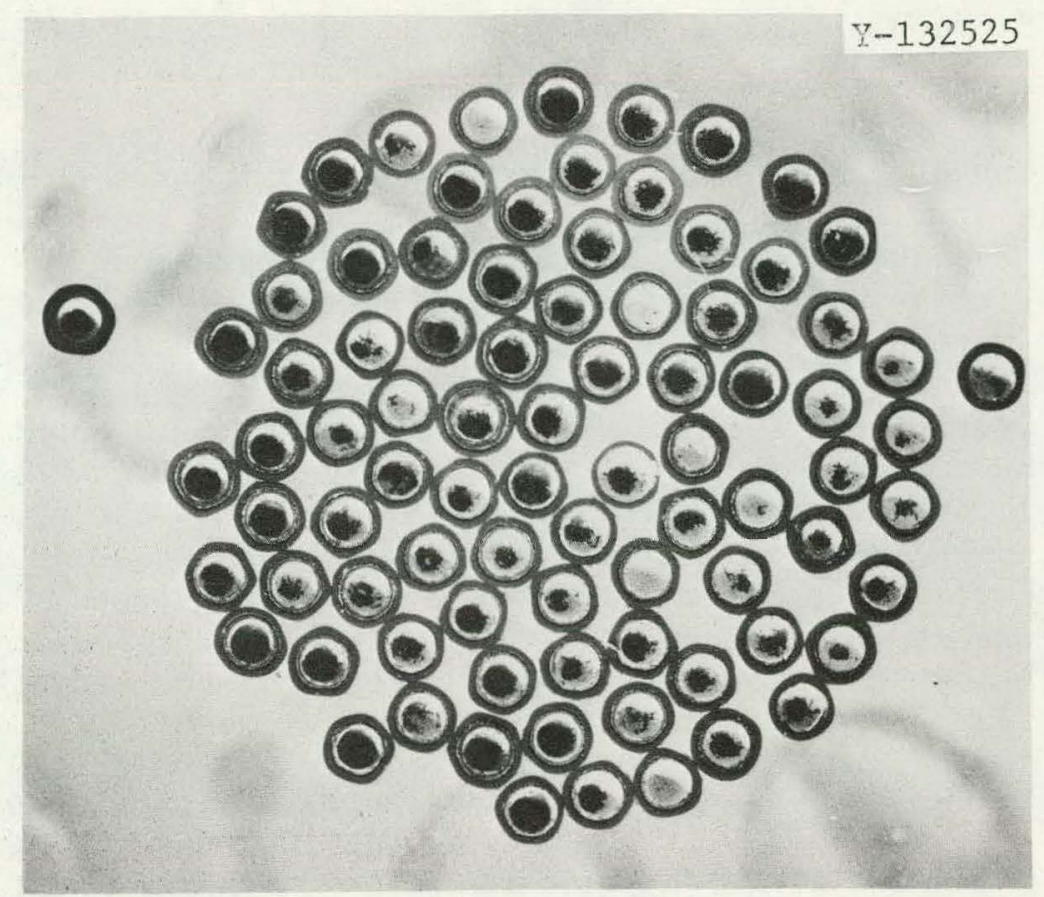

Fig. 13. The White Deposit Found on the Inner Surfaces of the Coatings After Plasma Oxidation. 7x.

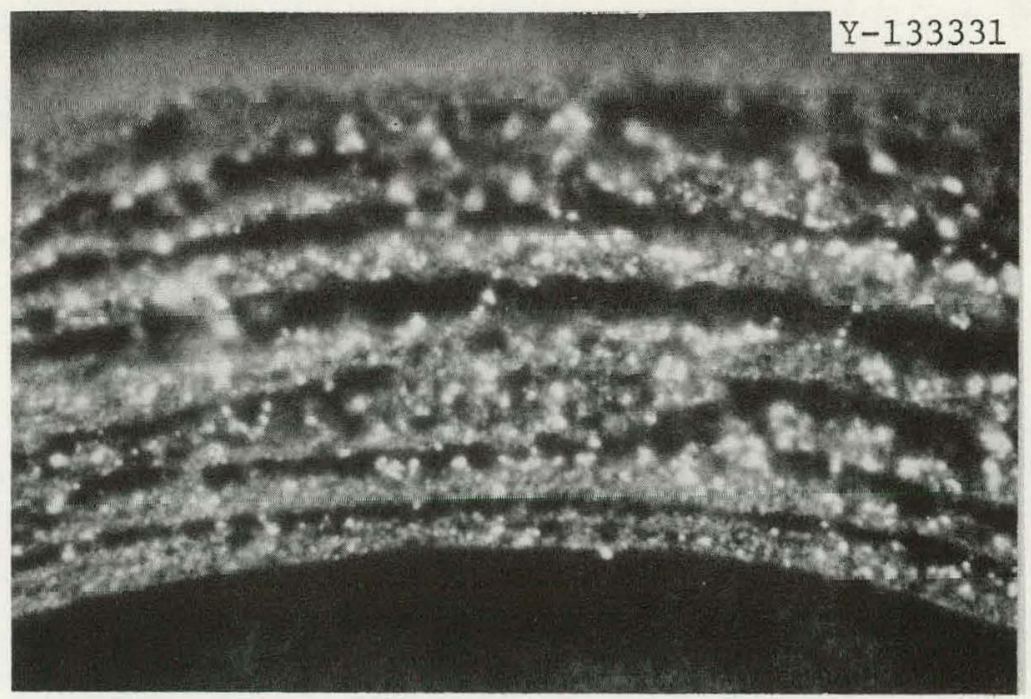

Fig. 14. Typical White Deposit Observed on Etched PyC Coating Previously Polished with Diamond Paste. Dark field illumination. 500x. 
IMPORTANCE OF THE LOCATION OF THE SAMPLE MOUNT IN THE LTA-302 UNIT DURING PLASMA OXIDATION OF PYC COATINGS

As mentioned earlier, the LTA-302 has two oxidation chambers with two available sample positions in each chamber. Two experiments were conducted to see if samples of the same coating etched equally in the different positions. In the first experiment, samples of the same coating type were placed in the front position of each chamber and oxidized simultaneously. The seven coatings of Table 2 were etched at rf power levels of 20,30 , and $40 \mathrm{~W}$ per chamber. In about half of these runs the coatings in one of the chambers would etch faster than the identical coating in the other chamber. At times the coatings in the right-hand chamber would etch more readily than those in the lefthand chamber and at other times the situation was reversed. An example of this difference is shown in Fig. 15. We could not find any property of the sample mounts to explain this behavior and, therefore, assumed that it is a variable characteristic of the equipment.

In the second experiment, identical coatings were etched with samples at all four positions simullaneously. In Fig. 16, dark ficld photomicrographs are shown for one set of samples (coating OR-2263-HT) that was etched at $30 \mathrm{~W}$ per chamber for $10 \mathrm{~min}$. The structures observed on each sample mount were photographed at three locations; the center of the circular particle array, the edge of the array closest to the plasma column, and the edge of the array opposite the plasma column. This was done to help assess the differences in the etch gradient at each position. Note that the samples in the rear positions etched faster than those in the front positions. Also, the samples in the front positions have more variation in the degree of etching, with the least amount of etching on the edge of the array opposite the plasma column and nearest the access door. Similar results were obtained for cuating OR-2274-IIT. Therefore, it appears that the front positions of the chambers can be used to enhance the etch gradient across lie particle array, and the rear positions can be used to produce more uniform etching across the particle array.

\section{ROLE OF THE OXYGEN FLOW RATE IN PLASMA OXIDATION OF PyC COATINCS}

The oxygen flow delivered to the plasma chambers was varied to determine its effect on the plasma erching process. Samples of cuating OR-2263-HT were etched for a total of $20 \mathrm{~min}$ at $30 \mathrm{~W}$ per chamber, with oxygen flow rates of 25,75 , and $150 \mathrm{~cm}^{3} / \mathrm{min}$ per chamber. Dark field photomicrographs were taken of each sample near the middle of the particle arrays, where the etching was most extensive. The photomicrographs are shown in Fig. 17. All three samples show the same type of etch structure and qualitatively appear to be etched to the same extent. Thus, these oxygen flow rates had little effect on the structure revealed or the etching rate. 

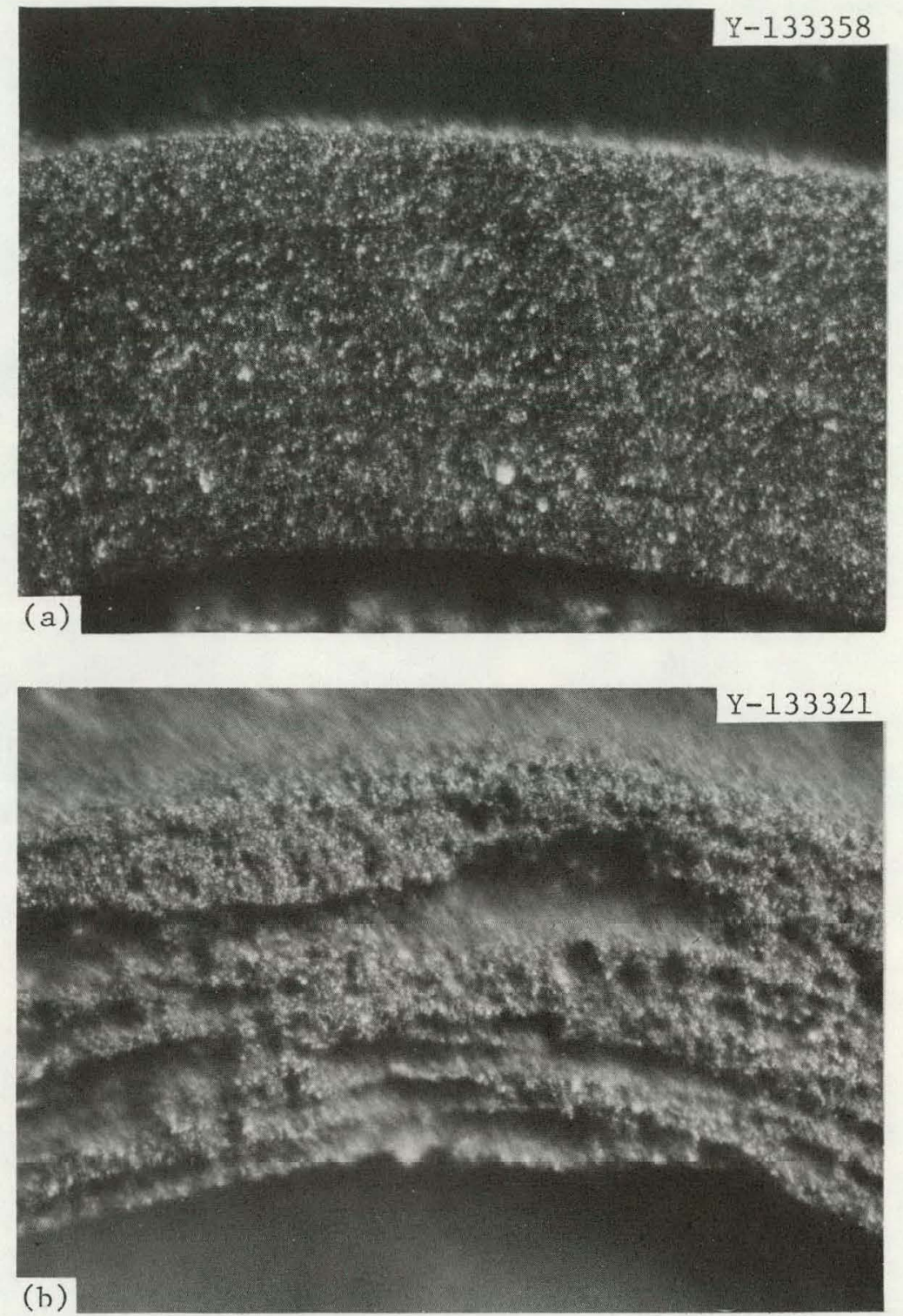

Fig. 15. The Difference in the Degree of Etching Received By Two Samples of Coating OR-2275-AHT, Which were Plasma Oxidized Simultaneously for $20 \mathrm{~min}$ at $20 \mathrm{~W}$ per Chamber. Dark field illumination. $500 \times$. (a) Left chamber and (b) right chamber. 

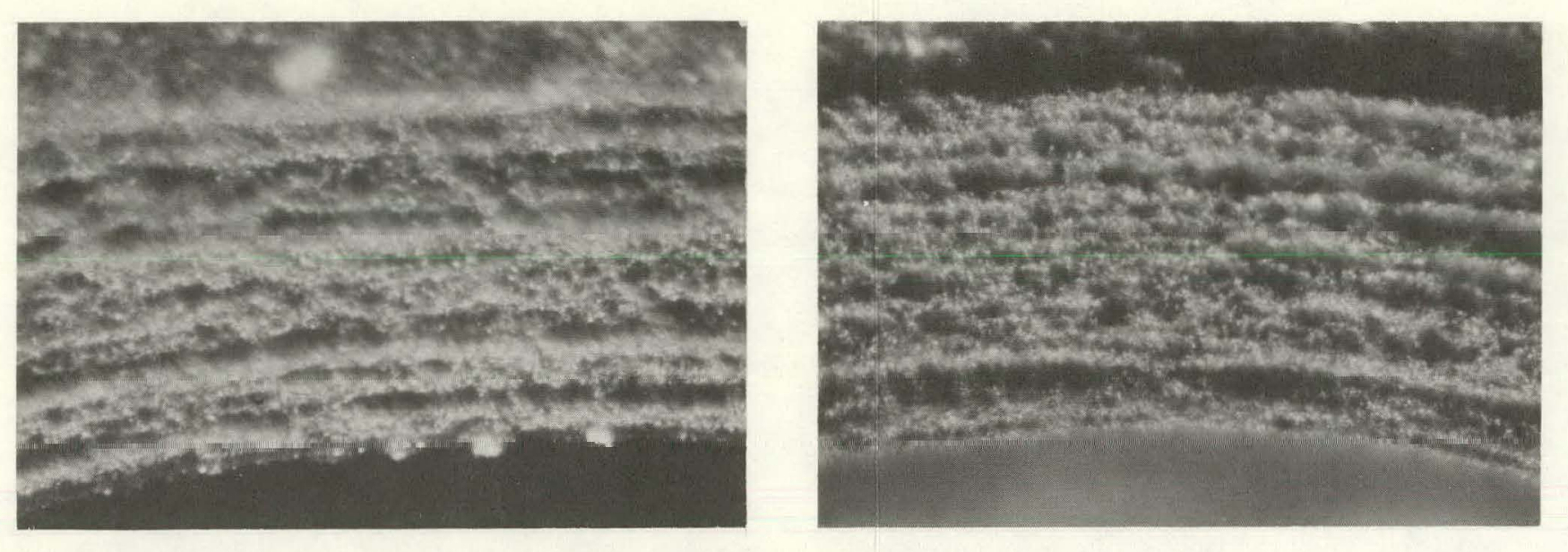

OPPOSITE PLASMA
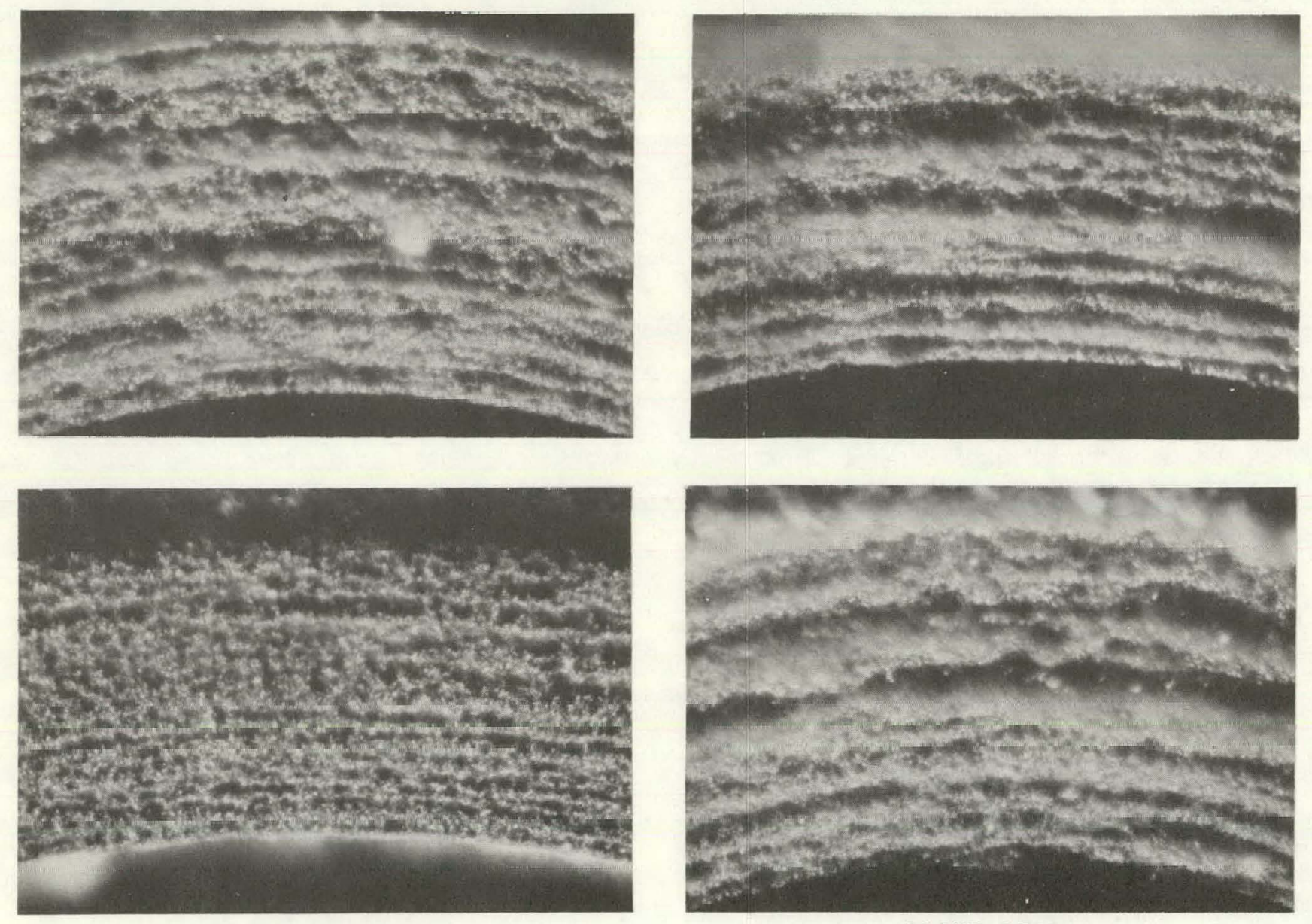

LEFT REAR

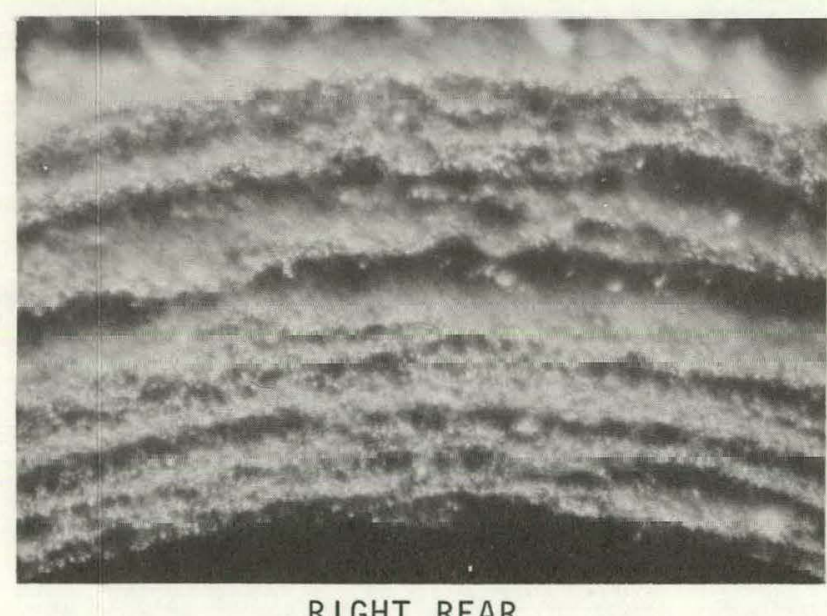

RIGHT REAR
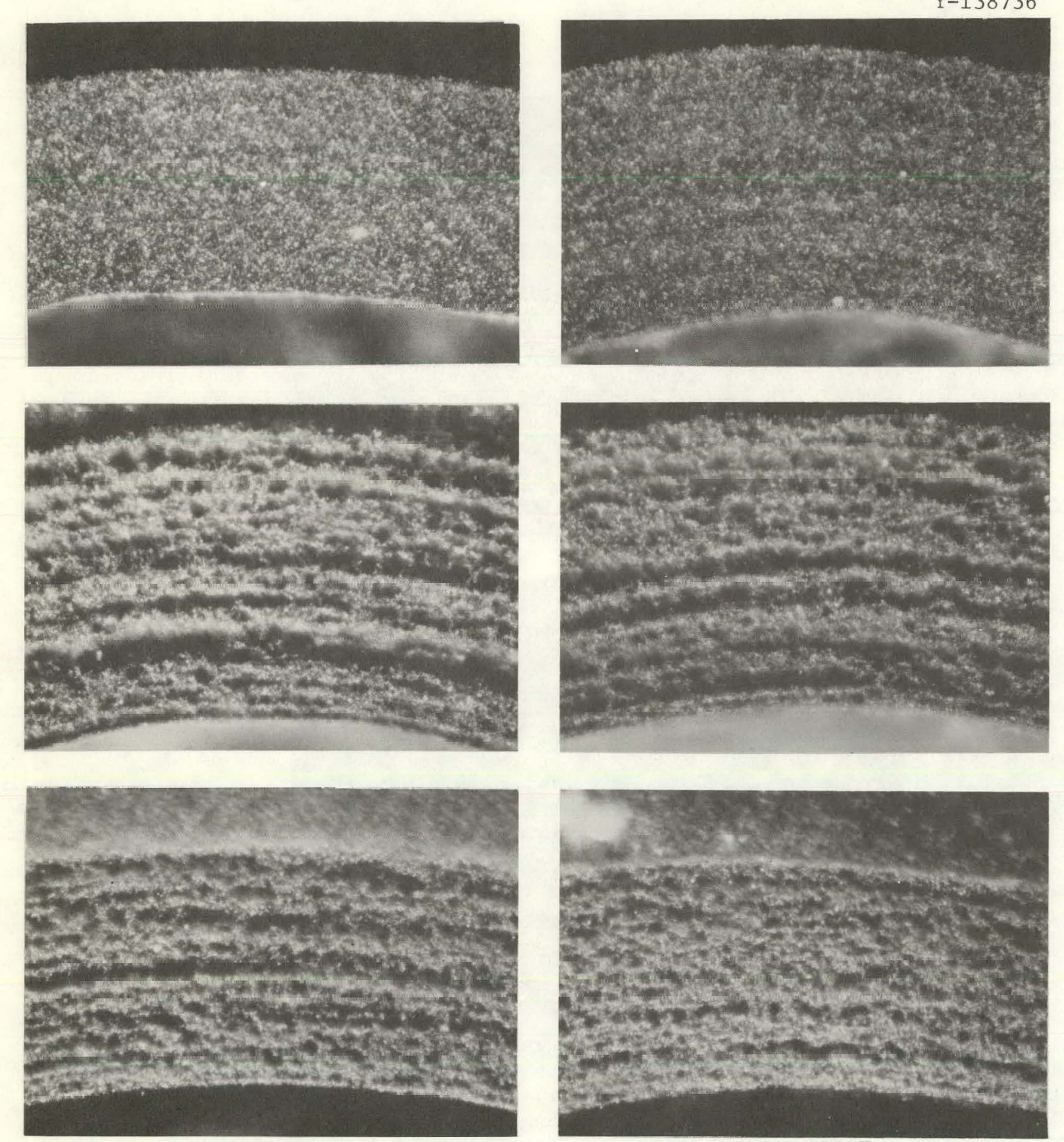

LEFT FRONT

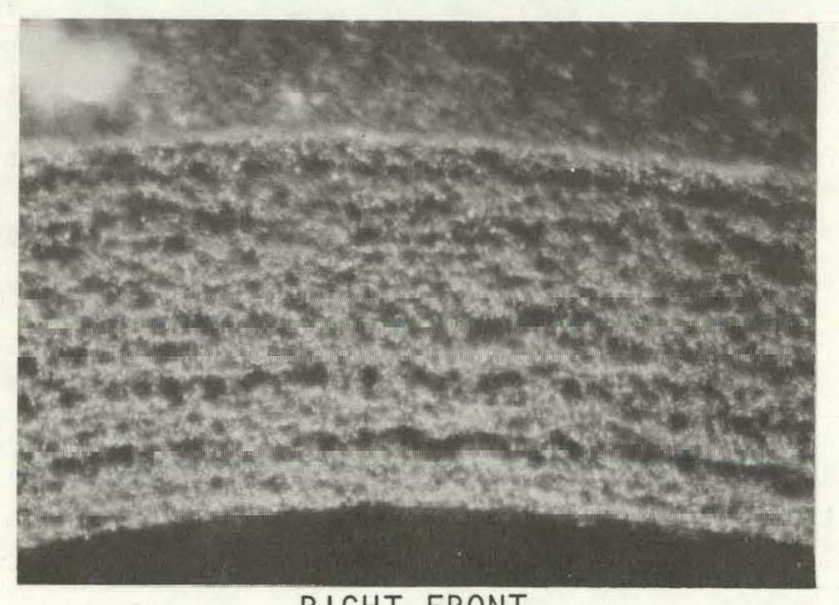

RIGHT FRONT

Fig. 16. The Effect of Sample Position on the Extent of Plasma Etching for Coating OR-2263-HT at $30 \mathrm{~W}$ per Chamber for 10 min. $500 \times$. 

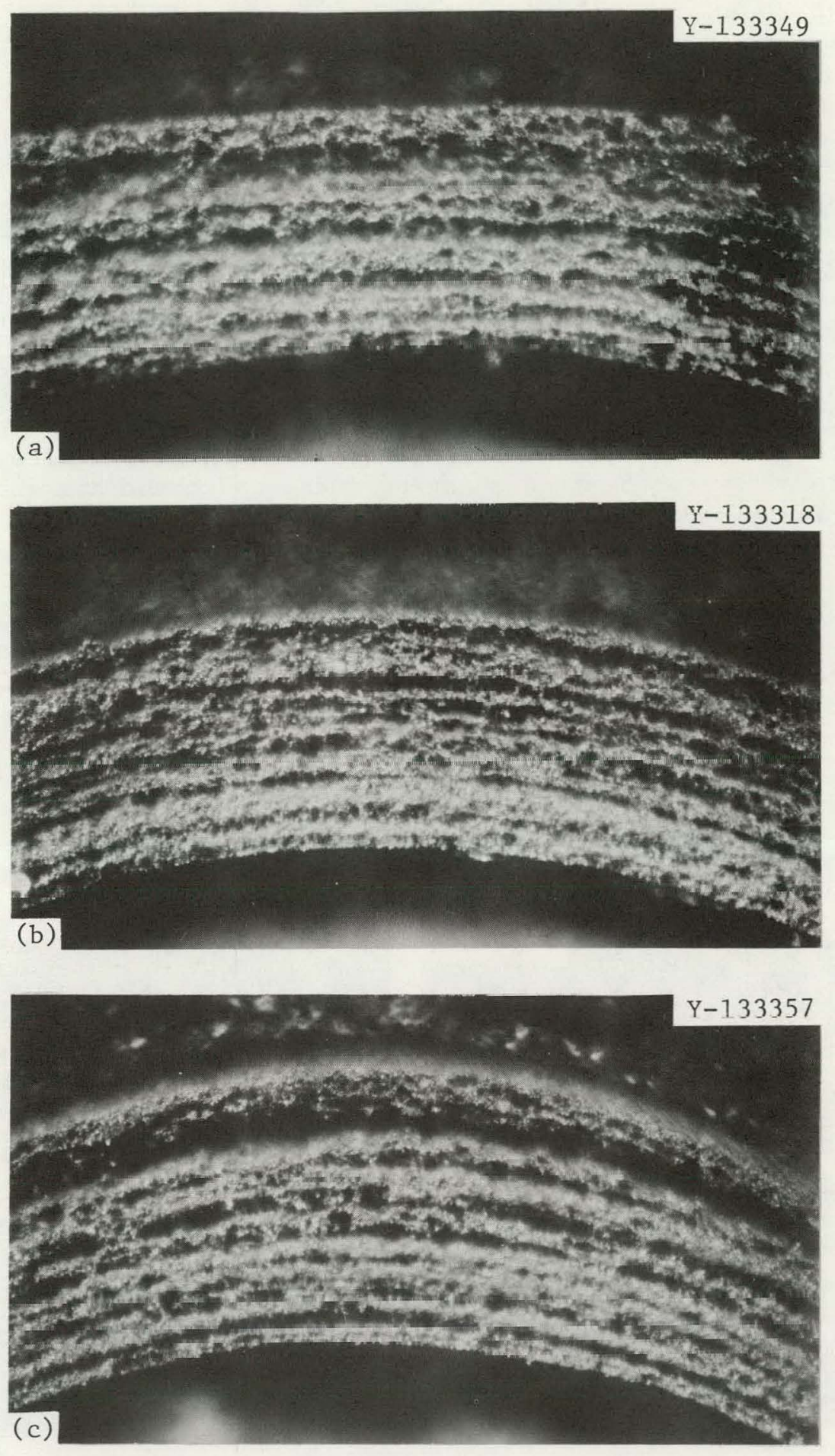

Fig. 17. Effect of Oxygen Flow Rate on the Plasma Etch Structure of Coating OR-2263-HT at $30 \mathrm{~W}$ per Chamber for $20 \mathrm{~min}$. Dark field illumination. 500x. Flow rate per chamber: (a) 25 , (b) 75 , (c) $150 \mathrm{~cm}^{3} / \mathrm{min}$. 


\section{EFFECT OF THE MOUNT TEMPERATURE \\ ON THE PLASMA OXIDATION RATE}

During experiments on the effect of the power level on the etching process we observed that most of the plasma etching that occurs in a PyC coating during a 10-min run period occurs during the last $5 \mathrm{~min}$. We also found that during a 10-min run the mount can become too hot to be handled without gloves. We evaluated the role of the mount temperature on the etching process in the experiments described in the following.

Identical samples of coating OR-2263-HT were etched for 5-min intervals at $20 \mathrm{~W}$ per chamber. However, one of the samples was preheated to $56^{\circ} \mathrm{C}$ in an oven before it was etched. The preheated sample etched very rapidly, while the sample that was initially at room temperature $\left(\sim 25^{\circ} \mathrm{C}\right)$ etched very little. Dark field photomicrographs were taken of each sample after two 5-min etching periods, and these are shown in Fig. 18. The photomicrographs were taken at the center of the particle arrays where the etching was most advanced. The preheated coating sample was actually judged to be overetched, while the sample that was not preheated had just started to develop significant etch detail. Therefore, the temperature of the sample mount during the etching process can greatly influence the plasma etching rate of a PyC coating. This could explain why typically most of the etching takes place in the last half of a 10 -min etch period.
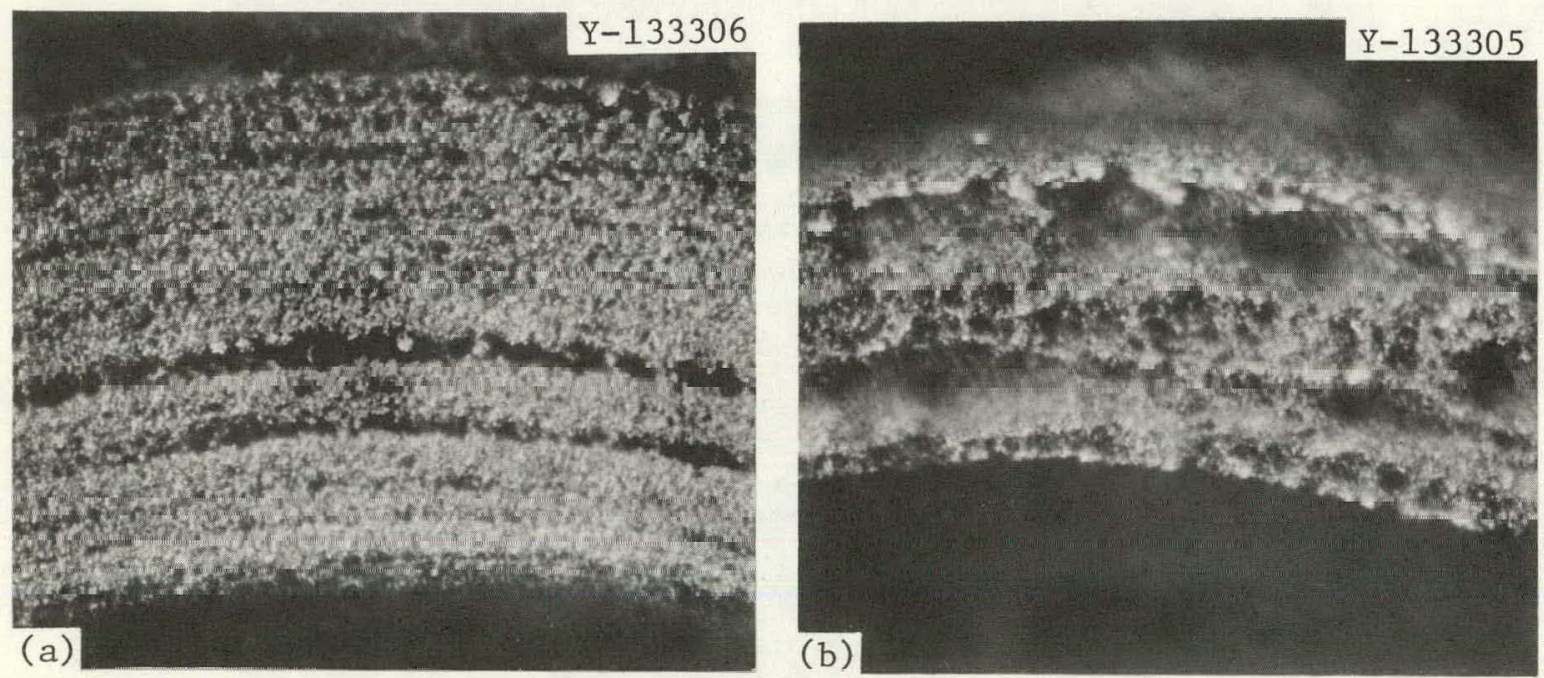

Fig. 18. Effect of Preheating Specimens of Coating OR-2263-HT Before Plasma Oxidation, $20 \mathrm{~W}$ per Chamber, Oxygen Flow $75 \mathrm{~cm}^{3} / \mathrm{min}$ per Chamber, Dark Field Illumination. 500×. (a) Without preheating and (b) with preheating. Etching time, $10 \mathrm{~min}$. 
The source of the heat accumulated in the mount and the resulting temperature rise were not determined. They could result from the oxidation of the PyC coatings or the epoxy mount, from ion and molecular bombardment by the plasma, or from eddy currents induced in the PyC coatings by the rf field. If the heat results from the oxidation of the PyC coatings or from eddy currents induced in the coatings, it may explain why radial etch gradients are observed in the sample mounts. The heat generated by a circular array of coatings would probably result in higher temperatures at the center of the array and thus increase the etching rate in this region. Disruption of the flow of the plasma to the edges of the particle array by the glass cover cap used to protect the edges of the epoxy mount is not an explanation, since the gradient also occurs when the cover cap is not used.

\section{EQUIVALENCE OF ETCH STRUCTURE CAUSED BY THE GRADIENT ACROSS} A MOUNT OR BY VARYING ETCHING TIME

Since many of the apparent etch structures change as etching proceeds, it was appropriate to study the etching sequence and attempt to identify the degree of etching that best characterizes the specific PyC coatings. The gradients in the particle mounts offered an alternate means of examining the changes in the etched structure with etching time. To ensure that the structures observed via these gradients actually corresponded to the changes observed in the etched structure with increasing etching time, a sample of coating OR-2295-HT was etched in 10-min intervals at $20 \mathrm{~W}$ per chamber. A particle in the mount was chosen for reference and after each 10-min etching period a dark field photomicrograph was made of the same area on the reference particle. The resulting sequence of photomicrographs was compared with photomicrographs taken of the etch gradient observed in a mount of the same coating that had been etched for a total of $30 \mathrm{~min}$ at the same rf power level. The etching sequence of the reference particle of coating OR-2295-HT with variable etching time is shown in Fig. 19, and the etch gradient for the same type of coating is shown in Fig. 20 for comparison. It is apparent from these photomicrographs that the observed etch gradient does represent the changes observed during plasma oxidation of a PyC coating with increased etching time. Note that the structure of Fig. 20(c) was obtained after 30 min of etching, while it took 100 min to reach the corresponding structure in Fig. 19(c). This difference occurs because the reference particle used in the etch structure vs time sequence in Fig. 19 was located on the edge of the particle array and thus etched more slowly than the particle shown from the etch gradient series.

Because the observed etch gradient is equivalent to the changes in the coating etch structures observed with increased etching time, it was possible and convenient to use the gradients to study these changes. This is considerably simpler in practice than trying to follow the etching sequence on a single particle coating as a function of time. 

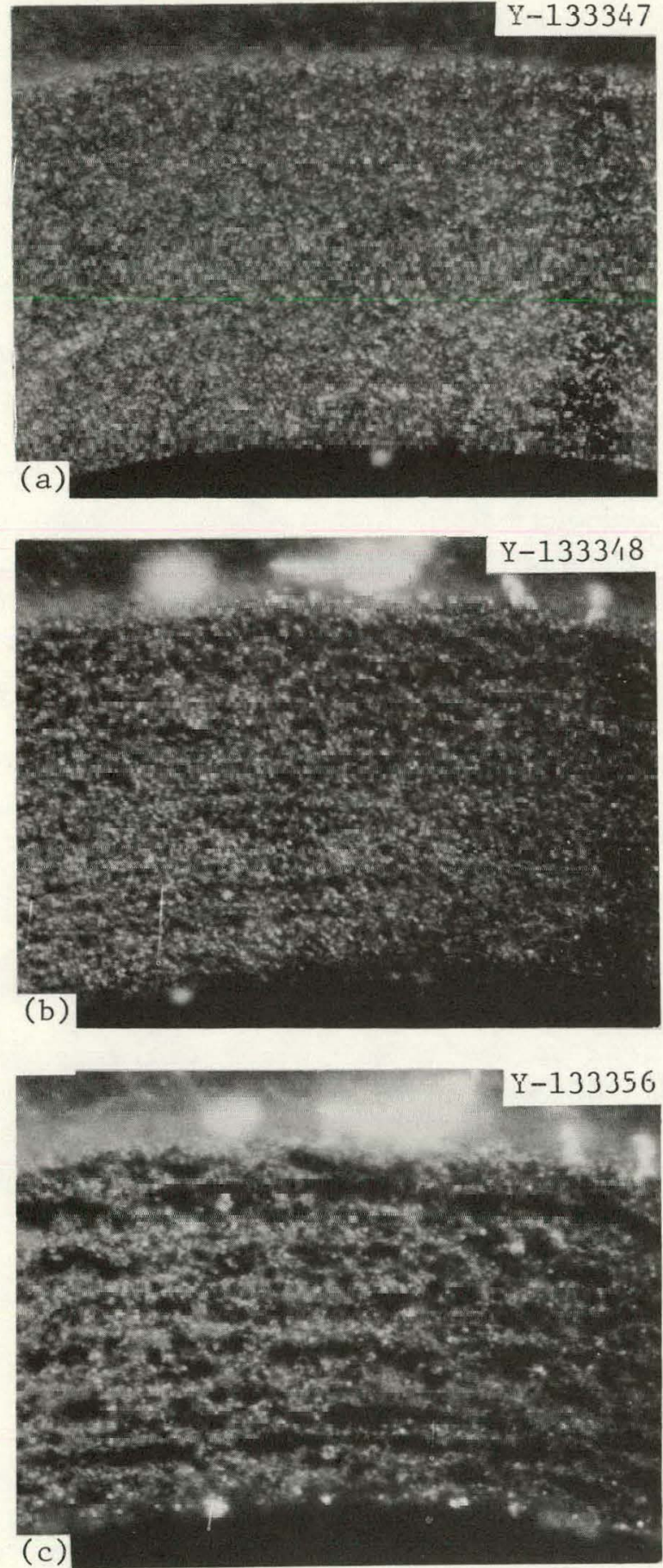

Fig. 19. Change in the Etch Structure of Coating OR-2295-HT as a Function of Time at $20 \mathrm{~W}$ per Chamber. Dark field illumination. $500 \times$. (a) $20 \mathrm{~min}$, (b) $50 \mathrm{~min}$, and (c) $100 \mathrm{~min}$.
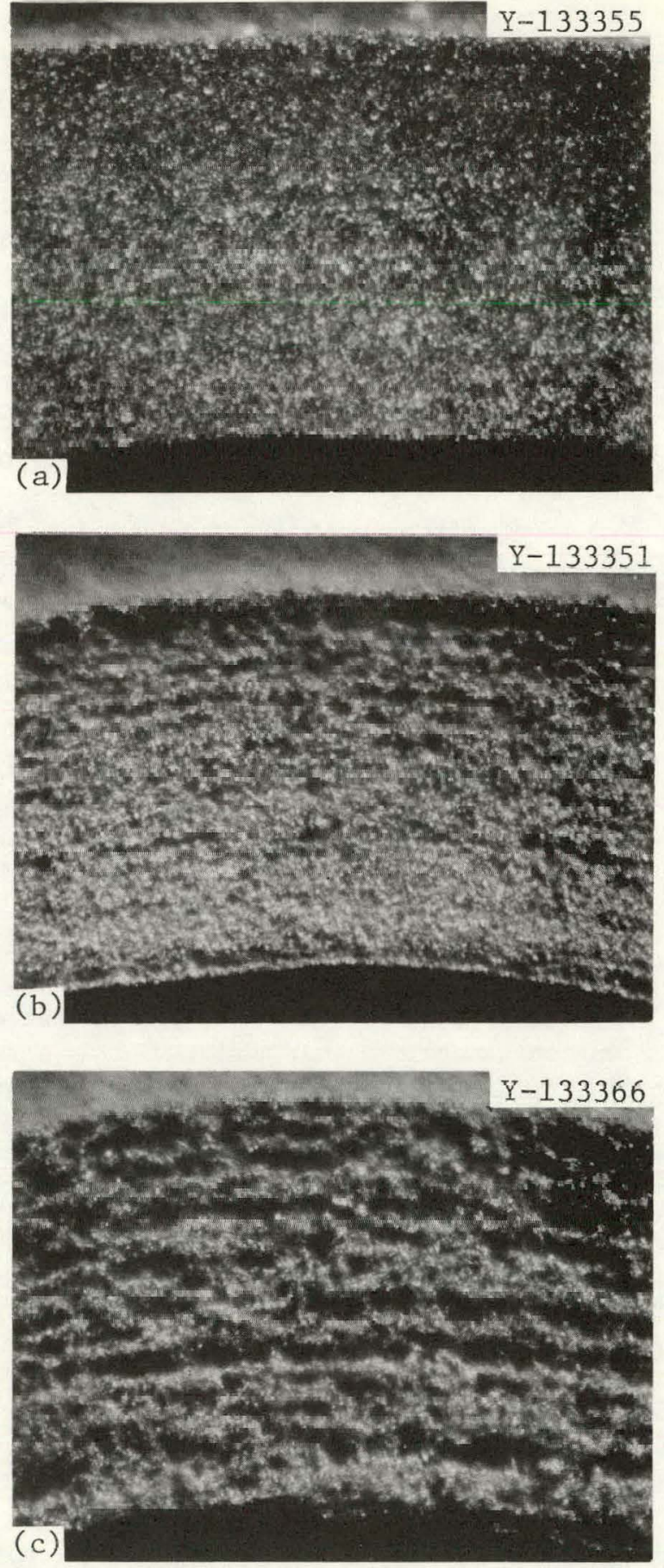

Fig. 20. Plasma Etching Gradient Observed in Coating OR-2295-HT, $20 \mathrm{~W}$ per Chamber, $30 \mathrm{~min}$. Dark field illumination. 500x. (a) Outside edge of the particle array, (b) near outside edge of the particle array, and (c) near the midradius of the array . 
CHANGES IN PyC COATING ETCH STRUCTURE WITH ETCHING TIME

A11 the coatings represented in Table 1 were etched at $20 \mathrm{~W}$ per chamber and photomicrographs were made of their etch gradients. Some examples of the changes that can be observed with increased plasma oxidation are shown for four different coatings in Figs. 21 through 24 . In coating OR-2297-AHT, Fig. 21, the etching begins in localized areas and would initially appear to represent the inhomogeneous type of etch structure (type 3) as in Fig. 21(b). As the etching proceeds, however, and surface relief becomes significant in other areas of the coating, the etched areas appear to be more uniformly distributed and the structure begins to resemble type 4, with a homogeneous distribution of oxidized PyC. The coating on OR-2294-HT represented in Fig. 22 initially etches uniformly. Then, as shown in Fig. 22(c), etching produces a surface in which the distribution of the readily oxidized carbon appears to be somewhat inhomogeneous. Finally, with still more etching the coating surface again appears to consist of a homogeneous distribution of readily oxidized carbon, as shown in Fig. 22(d). The plasma etching behavior of coating OR-2264-HT is illustrated in Fig. 23. Initially, this coating appears to have a homogeneous distribution of readily oxidizable carbon (type 4 ), but with further etching, the surface structure is more banded and begins to resemble the broken shell structure (type 2), as shown in Fig. 23(c) and (d). Finally, coating OR-2276-HT appears to have an etch structure characteristic of a coating consisting of closed shells of poorly oxidizable carbon (type 1) as in Fig. 24(b) and (c) and with increased etching, in (d), continues to have essentially the same appearance. Figures 21 through 24 also show that the amount of oxidized $\mathrm{PyC}$ in a given coating continually increases with etching time, so the apparent volume concentration of the readily oxidizable carbon in the coating is also a function of etching time. The above discussion illustrates the importance of the etching time in identifying the type of etch structure that typifies a particular coating. It also indicates the subjective nature of this characterization technique. It has been our experience that distinguishing a closed shell structure from a broken or interrupted shell structure is difficult. Thus, at this point, we cannot quantitatively characterize and differenliale the plasma elch struclure of various coatings except to identify obvious differences such as the closed shell structures of OR-2276-HT or the homogeneous structure of OR-2294-IIT. But for the present, even though the method is not completely definitive, the coating is best characterized by plasma oxidation using an etch gradient series that illustrates the various changes of the etch structure to be expected with etching time. 

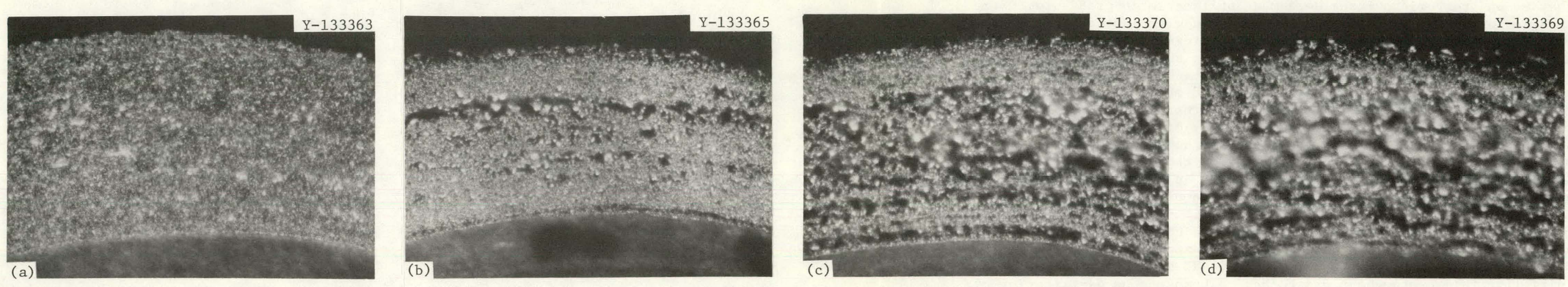

Fig. 21. The Etch Gradient as Shown by Dark Field Illumination for Coating OR-2297-AHT,

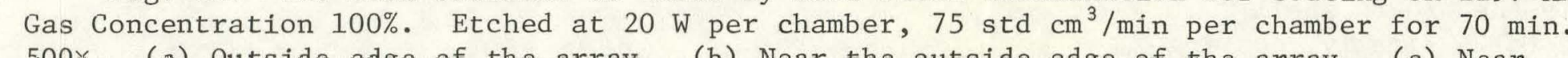
the midradius of the array. (d) Near the center of the array.
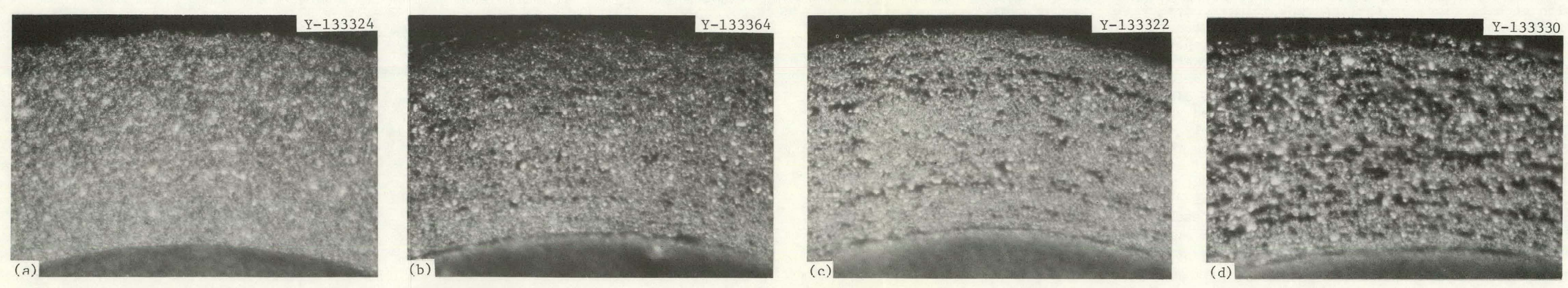

Fig. 22. The Etch Gradient as Shown by Dark Field Illumination for Coating OR-2294-HT, Gas Concentration $50 \%$. Etched at $20 \mathrm{~W}$ per chamber, $75 \mathrm{std} \mathrm{cm}^{3} / \mathrm{min}$ per chamber, for $60 \mathrm{~min}$. midradius of the array. (d) Near the center of the array. 

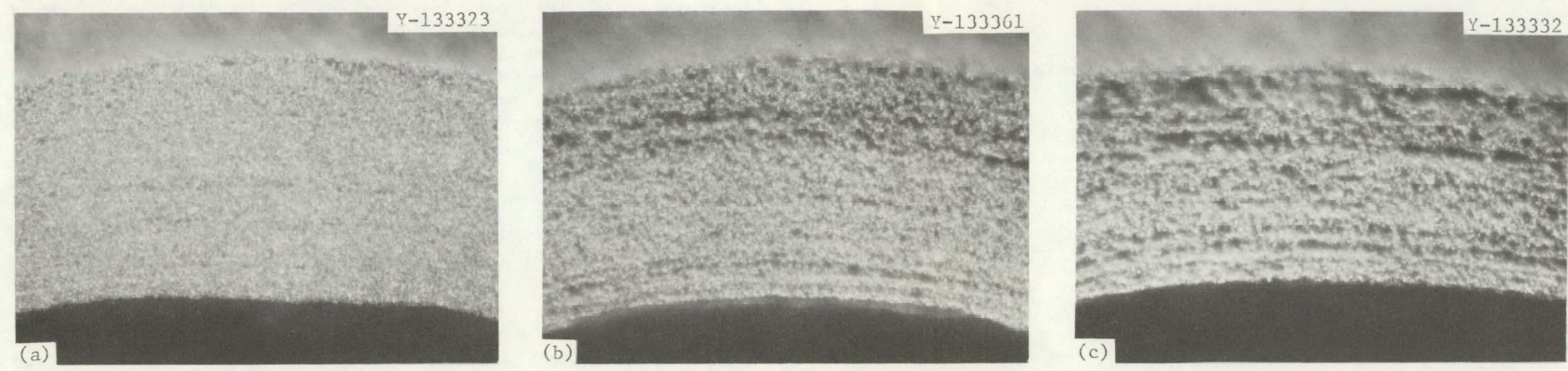

Fig. 23. The Etch Gradient as Shown by Dark Field Illumination for Coating OR-2264-HT, Gas Concentration $25 \%$. Etched at $20 \mathrm{~W}$ per chamber, $75 \mathrm{std} \mathrm{cm} 3 /$ min per chamber for $80 \mathrm{~min}$ the midradius of the array. (d) Near the center of the array.
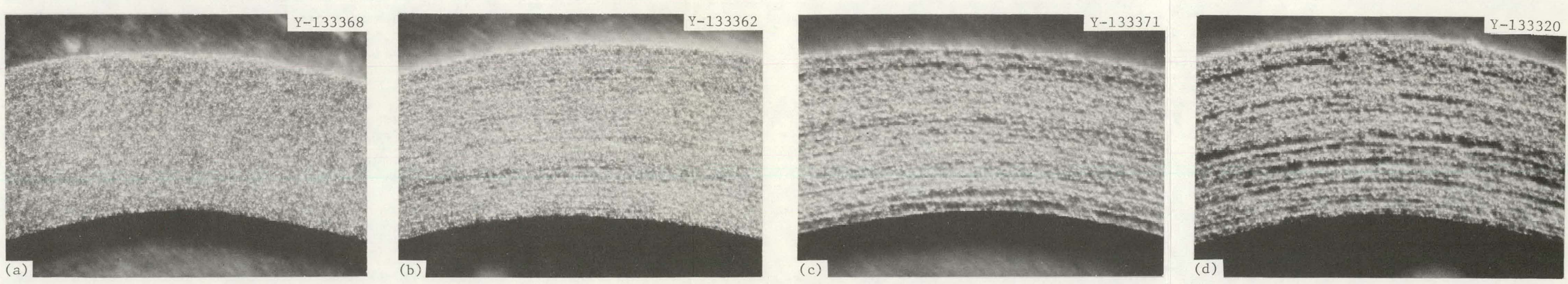

Fig. 24. The Etch Gradient as Shown by Dark Field Illumination for Coating OR-2276-HT, Gas Concentration $15 \%$. Etched at $20 \mathrm{~W}$ per chamber, $75 \mathrm{std} \mathrm{cm}^{3} / \mathrm{min}$ per chamber, for $50 \mathrm{~min}$.

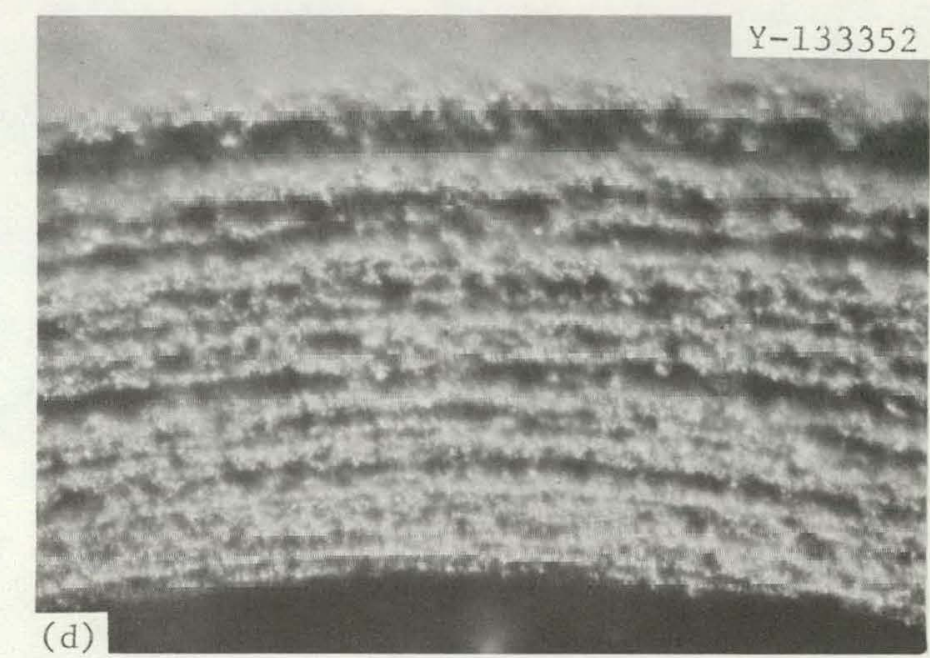




\section{RELATIONSHIP BETWEEN PYC COATING DEPOSITION PARAMETERS} AND PLASMA ETCH STRUCTURE

We have observed a clear relationship between the MAPP gas concentration used to deposit the coatings and the type of etch structure that developed during plasma oxidation of polished midplane sections. The coatings shown in Fig. 21 through 24 were all deposited at $1275^{\circ} \mathrm{C}$ at approximately the same rate, and, therefore, the differences in the plasma etch structures observed should be due to the gas concentration alone. Note that there appears to be a gradual transition from the inhomogeneous type of etch structure through the homogeneous and broken shell structures to the closed shell structure as the hydrocarbon gas concentration employed for deposition is reduced.

No obvious relation was observed between the etched structures and the deposition rates or deposition temperatures represenled in Table 1 .

\section{RELATIONSHIP BETWEEN THE INITIAL POROSITY IN THE PyC COATING AND THE PLASMA ETCH STRUCTURE}

Pits are usually observed in the midplane section of PyC coatings following normal metallographic polishing, and these appear to be related to the etch structures that develop in the coating during plasma oxidation. When these pits are randomly distributed throughout the coating, the etch structure that develops is characteristic of either the closed shell or the so-called homogeneous type. When the pits are concentrated into small regions in the coating, the subsequent plasma etch structure indicates an inhomogeneous distribution of readily oxidizable carbon (type 3 structure). The pitted as-polished structure of areas in the coatings on two batches of particles is compared with their plasmaoxidized structures in Fig. 25 and 26. Note the correspondence between the areas where the pits are concentrated in Fig. 26(a) and the heavily etched areas of Fig. 26(b).

To determine if the observed pits were the result of porosity in the coating rather than artifacts introduced during polishing, fracture surfaces of PyC coating fragments from coatings OR-2263-HT and -2274-HT were examined in the scanning electron microscope (SEM). Porosity was present in both coatings, as can be seen in Figs. 27 and 28. Areas of high porosity were observed in coating OR-2274-HT, while the pores in OR-2263-HT were uniformly distrihuted just as they appeared in the polished sections. The spheroidal carbon growth features that make up these coatings are easily recognized in Figs. 27 and 28.

The specific role that the pores in the PyC coatings play in determining the plasma etching behavior of the material is not clear at present. The location of local pore concentrations within a coating does correlate reasonably well with the areas where oxidation occurs most rapidly during plasma etching. The more porous areas may only be regions 

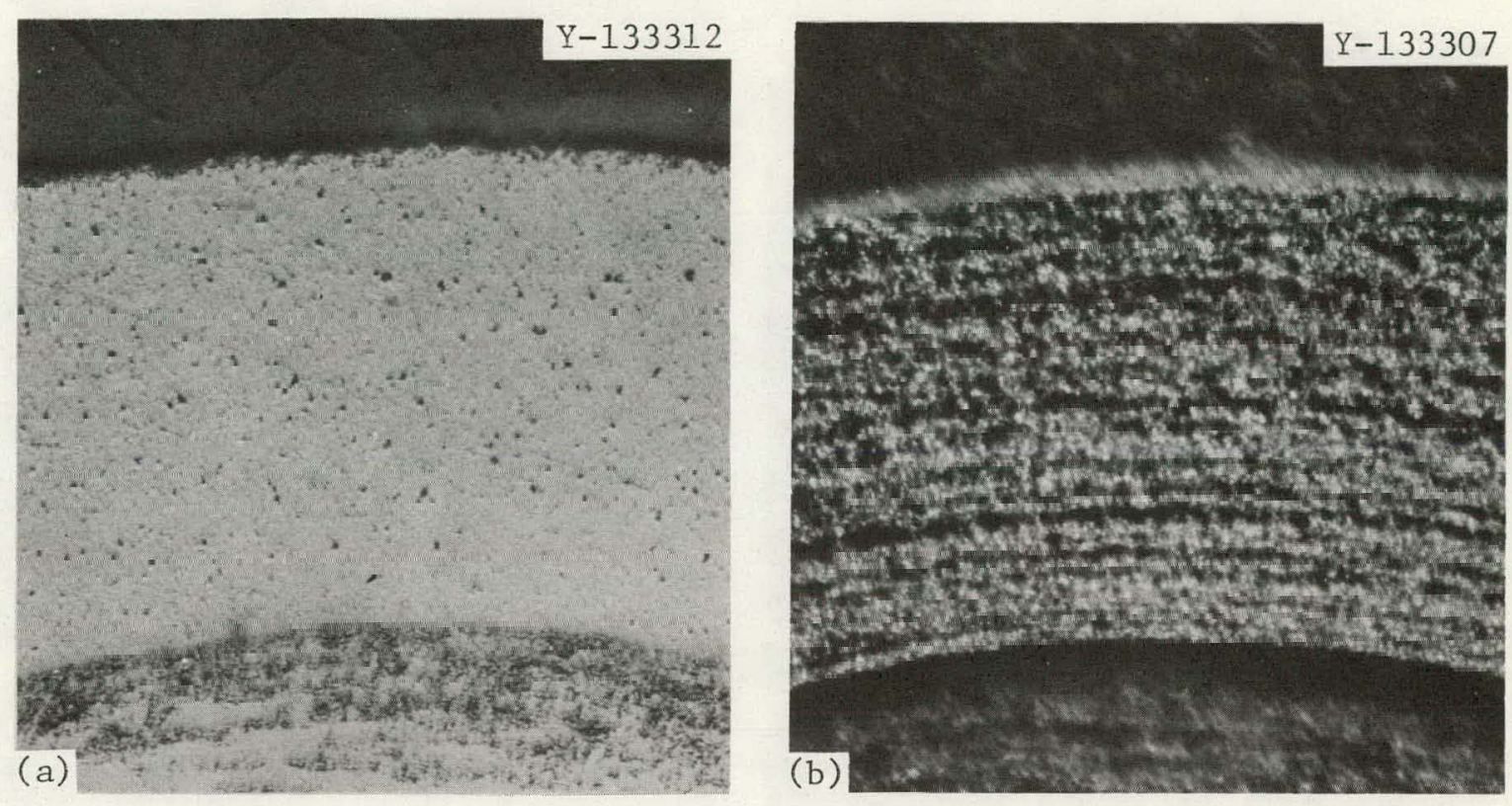

Fig. 25. Coating OR-2263-HT. 500×. (a) As-polished, bright field and (b) after etching at $20 \mathrm{~W}$ per chamber for $30 \mathrm{~min}$, dark field.
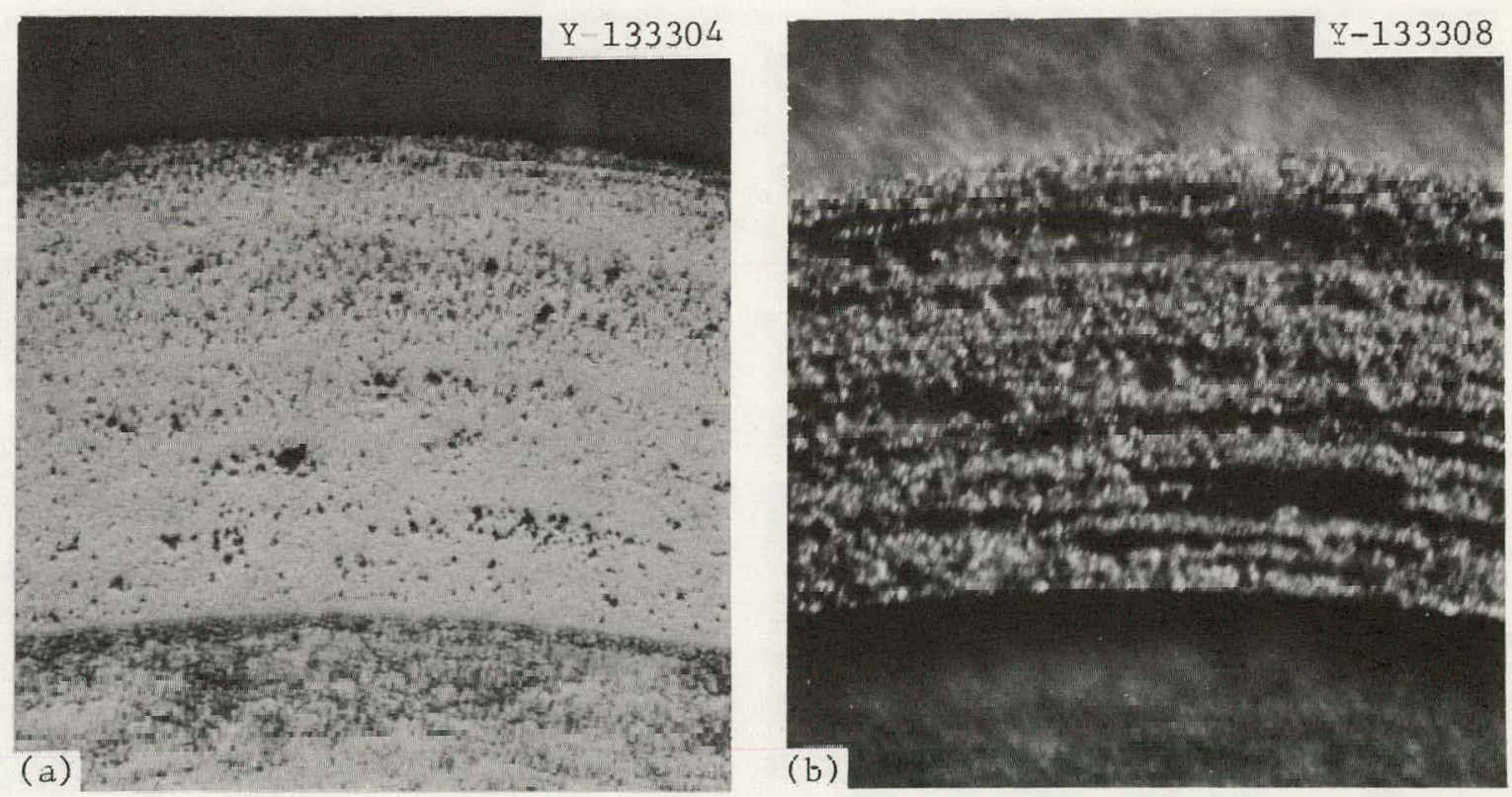

Fig. 26. Coating OR-2274-HT. 500×. (a) As-polished, bright field and (b) after etching at $20 \mathrm{~W}$ per chamber for $90 \mathrm{~min}$, dark field. 

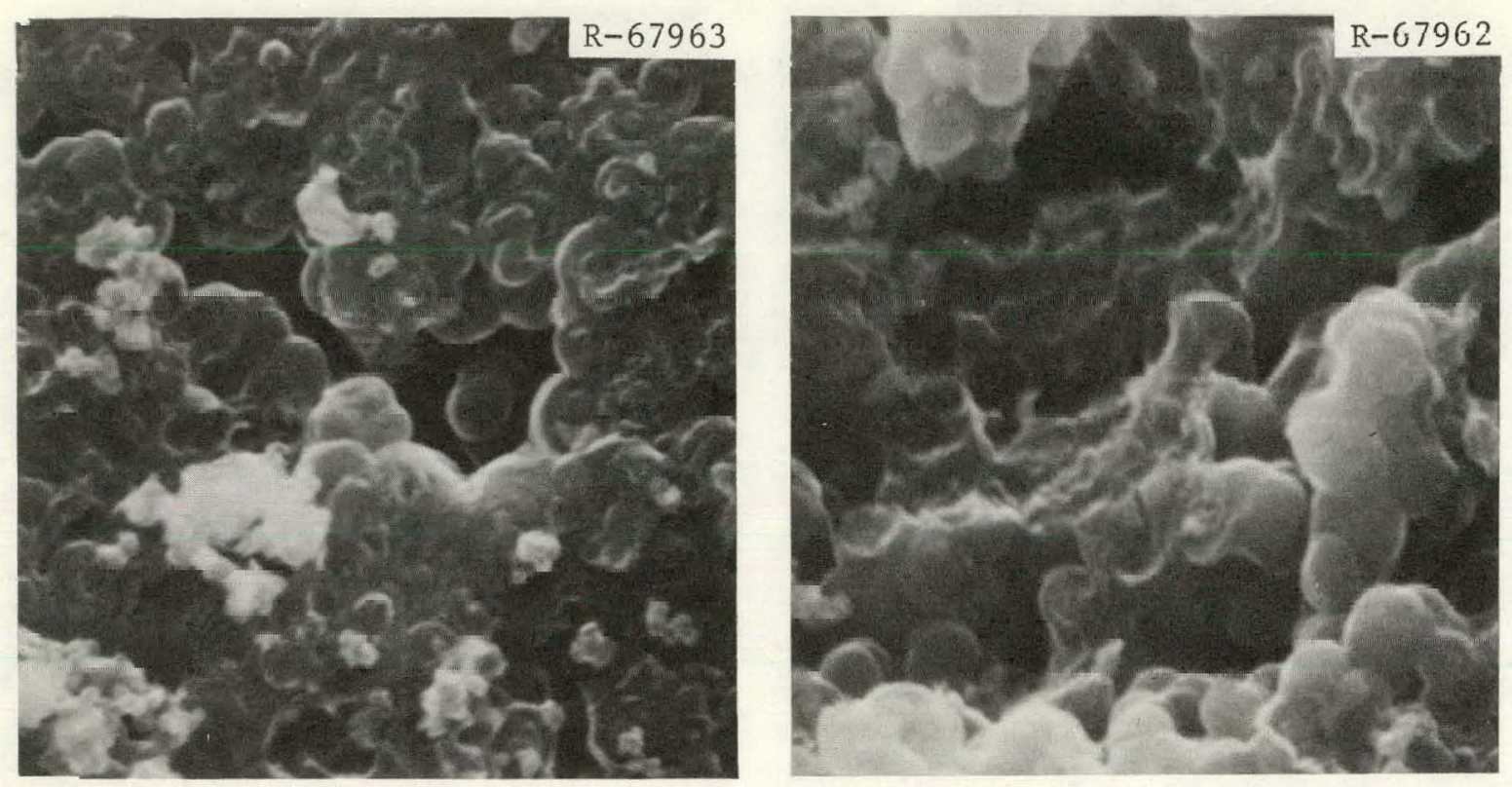

Fig. 27. Typical Porosity at Two Locations in Fractured Annealed PyC Coating for OR-2274-HT as Shown by the SEM. 10,000×.
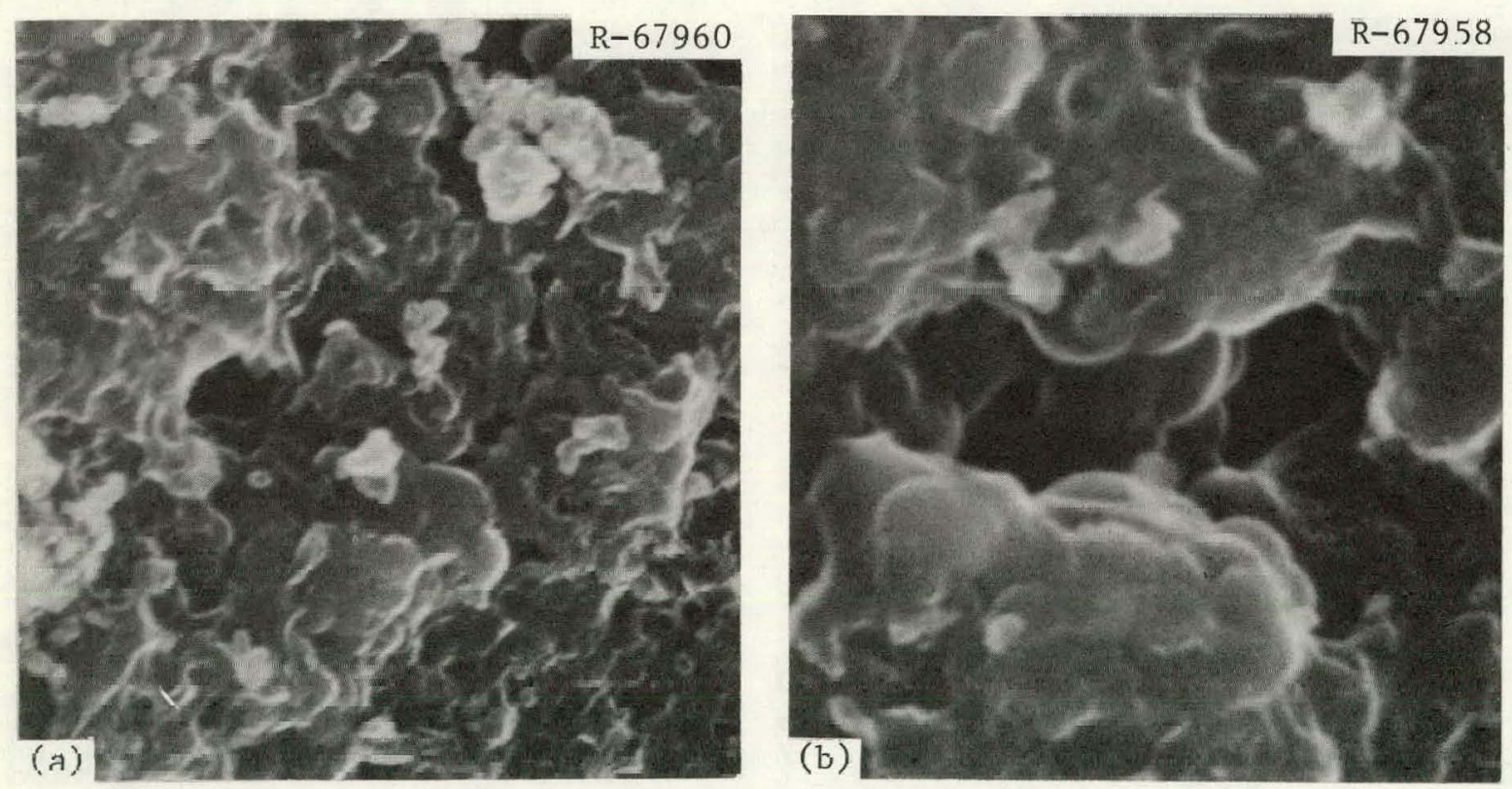

Fig. 28. Typical Porosity in Fractured Annealed PyC Coating OR-2263-HT as Shown by the SEM. (a) $10,000 \times$. (b) $20,000 \times$. 
where carbon oxidation is initiated, with subsequent oxidation and etching being more dependent upon the crystalline structure of the PyC, as suggested by Luhleich et al. ${ }^{4-15}$ Localized etching, therefore, may be due to large local pore concentrations, while etching in the remainder of the coating may be due to the crystalline structure of the carbon. Another possibility that should be considered, however, is that the pore structure itself is responsible for the etched structure that develops. Figure 29 shows the sequence of etching that was observed at the same location on a midplane section of coating OR-2295-HT in scanning electron micrographs. In the as-polished state a few large pores are visible along with a large number of what appear to be small depressions in the surface. We were not able to observe these features at high magnification because of the relatively poor contrast for this material in the SEM. As the plasma etching progresses, the pores grow much larger and the depressions grow into small pores or pits. Note in Fig. 29(b) that a polishing scratch appears that was not visible in Fig. 29(a). This may be due to carbon debris from the polishing operation filling a scratch and being easily oxidized later in the first etch cycle. It appears possible that the depressions observed in the polished coating are pores that are also filled with this very fine carbon resulting from the polishing procedure. It is also possible that the depressions are areas of the "carbon-black-like" or CBC material referred to by Luhleich, 14-15 and that the surface depressions are caused by pullout during the polishing. In either case, it appears that the depressions originally observed in the as-polished surface grow during plasma oxidation and eventually merge to form the larger oxidized areas in the final etch structure.

\section{CONCLUSIONS}

1. The final oxygen-plasma-etched structure developed in PyC coatings on HTGR fuel particles is independent of the rf power level. used in the range of 20 to $40 \mathrm{~W}$ per chamber for the equipment used in this investigation.

2. The time required to plasma etch a given coating is greatly reduced at higher rf power levels, but the ctching process cannot be conveniently monitored at the higher power levels with the apparatus used in this work.

3. Coatings deposited from MAPP gas at $1325^{\circ} \mathrm{C}$ and having densities from 1.84 to $1.96 \mathrm{~g} / \mathrm{cm}^{3}$ etched faster than those deposited at $1275^{\circ} \mathrm{C}$ and having densities from 1.99 to $2.05 \mathrm{~g} / \mathrm{cm}^{3}$.

${ }^{14} \mathrm{H}$. Luhleich et al., "Determination of the Distribution of Amorphous Regions in Pyrocarbon Coatings by Means of 'Cold Oxidation, '" Z. AnaZ. Chem. 255: 97-103 (1971).

${ }^{15} \mathrm{~K}$. Bongartz et al., Improvements in Characterization of Pyrolytic Deposited Carbon, JüL-1078-RW (June 1974). 

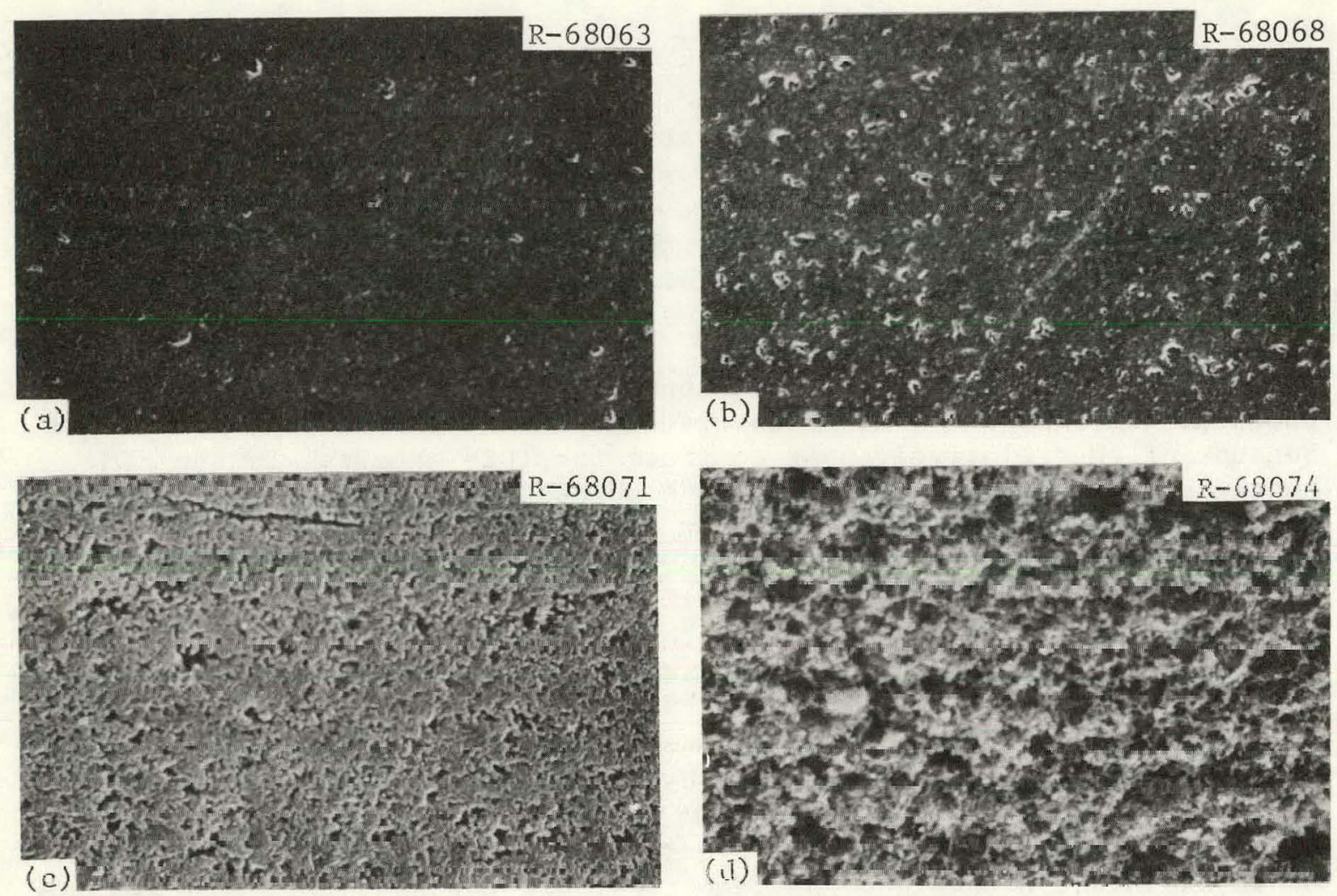

Fig. 29. The Effect as Shown by the SEM of Increased Plasma Oxidation Time on Coating OR-2295-HT at $20 \mathrm{~W}$ per Chamber. 1000×. (a) Aspolished. (b) After $5 \mathrm{~min}$. (c) After $10 \mathrm{~min}$. (d) After $18 \mathrm{~min}$.

4. Gradients in the degree of etching that appear in the coated particle sample mounts correlate well with the various stages of plasma etching that are observed for the same PyC coating with increased etching time.

5. Gradients or differences in the degree of etching developed across a typical coated particle mount are useful and reduce the need to know and use precise etching times for every coating type of interest.

6. It may be possible to use standard etching times at high power levels on a variety of PyC coating types if elongated particle arrays are used in the metallographic mount to enhance the etching gradients.

7. The degree of etching developed in identical samples in the two oxidation chambers of the LTA-302 oxygen plasma unit is not always equal and is very unpredictable.

8. The oxygen flow rate in the equipment used in this study has little effect on the plasma etching rate of the particle coatings in the flow range of 25 to $150 \mathrm{~cm}^{3} / \mathrm{min}$ per chamber.

9. The temperature of the PyC coatings during plasma oxidation is an important factor in determining the etching rate. The etching rate is greatly increased when the initial temperature of the PyC coating is raised as 1 ittle as $30^{\circ} \mathrm{C}$ above room temperature. 
10. The type of etch structure that is developed during plasma oxidation of PyC coatings is a function of the characteristics of the coating and the total etching time.

11. The plasma etch structure produced in a PyC coating is strongly related to the concentration of the hydrocarbon gas employed in the coating furnace. For the MAPP-gas-derived coatings, there is a gradual transition from etch structures associated with an inhomogeneous distribution of readily oxidizable carbon at high gas concentrations to structures with a closed spherical shell structure at low gas concentrations.

12. The distribution of pores or pits in the PyC coating following metallographic polishing is related to the plasma etch structure subsequently observed, but the exact nature of this relationship is not completely understood at present.

\section{ACKNOWLEDGMENTS}

The authors wish to express their appreciation to R. L. Beatty and C. Hamby, who prepared the PyC coatings studied in this investigation. The invaluable assistance of R. S. Crouse and especially E. T. Rose of the Metallography Group of the Metals and Ceramics Division was essential to this work and is gratefully acknowledged. The authors also acknowledge the assistance of $S$. Peterson for careful technical editing and Julia L. Bishop for typing and makeup of the report. 
THIS PAGE

WAS INTENTIONALLY

LEFT BLANK 


\author{
ORNL/TM-5308 \\ UC-77 (Gas-Cooled \\ Reactor Technoḷogy)
}

\title{
INTERNAL DISTRIBUTION
}

1-2. Central Research Library

3. Document Reference Section

4-23. Laboratory Records Department

24. Laboratory Records, ORNL RC

25. ORNL Patent Office

26. P. Angelini

27. R. L. Beatty

28. E. S. Bomar

29. R. A. Bradley

30. A. J. Caputo

31. J. A. Conlin

32. T. H. Coobs

33. W. H. Cook

34. D. A. Costanzo

35. F. L. Culler

36. J. E. Cunningham

37. R. G. Donnelly

38. W. P. Eatherly

39. J. I. Federer

40. R. L. Hamner

41. R. F. Hibbs

42-44. M. R. Hill

45. F. J. Homan

46. J. D. Jenkins
47. D: R. Johnson

48. M. J. Kania

49-50. P. R. Kasten

51. R. K. Kibbe

52. W. J. Lackey, Jr.

53. T. B. Lindemer

54. E. L. Long, Jr.

55. A. L. Lotts

56. J. P. Mathers

57. C. S. Morgan

58. M, T. Morgan

59. R. L. Pearson

60. W. H. Pechin

61. H. Postma

62. I M Robbinș

63. J. D. Sease

64. D. P. Stinton

65-74. V. J. Tennery

75. T. N. Tiegs

76. G. W. Weber

77. J. R. Weir, Jr.

78. C. S. Yust

79. S. H. Jury (Consultant)

80. H. T. Roland (Consultant)

EXTERNAL DISTRIBUTION

81-82. ERDA DIVISION OF NUCLEAR FUEL CYCLE AND PRODUCTION, Washington, DC 20545

Director

83-84. ERDA DIVISION OF NUCLEAR RESEARCH AND APPLICATION, Washington, DC 2054.5

Director

85-86. ERDA OAK RIDGE OPERATIONS OFFICE, P.O. BOX E, Oak'Ridge, TN 37830

Director, Reactor Division

Research and Technical Support Division 


\section{EXTERNAL DISTRIBUTION (Continued)}

87-253. ERDA TECHNICAL INFORMATION CENTER, Office of Information Services, P.0. Box 62, Oak Ridge, TN 37830

For distribution 'as shown in TID-4500 Distribution Category, UC-77 (Gas-Cooled Reactor Technology)

254-291. ERDA Exchange Agreements with Germany and Dragon Project 